\title{
Generalizability and Applicability of Model- Based Business Process Compliance-Checking Approaches - A State-of-the-Art Analysis and Research Roadmap
}

\author{
Jörg Becker, European Research Center for Information Systems (ERCIS), University of Münster, Germany, e-mail: becker@ercis.org \\ Patrick Delfmann, European Research Center for Information Systems (ERCIS), University of Münster, Germany, e-mail: delfmann@ercis.org \\ Mathias Eggert, European Research Center for Information Systems (ERCIS), University of Münster, Germany, e-mail: eggert@ercis.org \\ Sebastian Schwittay, Deutsche Bank AG, Eschborn, Germany, e-mail: sebastian.schwittay@db.com
}

\begin{abstract}
With a steady increase of regulatory requirements for business processes, automation support of compliance management is a field garnering increasing attention in Information Systems research. Several approaches have been developed to support compliance checking of process models. One major challenge for such approaches is their ability to handle different modeling techniques and compliance rules in order to enable widespread adoption and application. Applying a structured literature search strategy, we reflect and discuss compliance-checking approaches in order to provide an insight into their generalizability and evaluation. The results imply that current approaches mainly focus on special modeling techniques and/or a restricted set of types of compliance rules. Most approaches abstain from real-world evaluation which raises the question of their practical applicability. Referring to the search results, we propose a roadmap for further research in model-based business process compliance checking.
\end{abstract}

JEL classification: L5O; M42; M48

Keywords: business process modeling, business process compliance management, business process compliance checking, regulation, legal requirements

Manuscript received April 4, 2012, accepted by Karl Inderfurth (Operations and Information Systems) August 7, 2012.

\section{$1 \quad$ Introduction}

Since the passing of the Sarbanes-Oxley Act (SOX) (Sarbanes-Oxley Act 2002) the world's regulation environment has changed significantly. This has seen companies confronted with a steady increase of rules that have serious effects on internal business processes. The compliance management of firms is faced with a challenging task: On the one hand, the audit of business processes in order to comply with regulations, such as SOX, the minimum requirements for risk management (BaFin 2010) or money laundry laws (i.e., U.S. Money Laundering Suppression Act of 1994), becomes more and more sophisticated. On the other hand, organizations consist of hundreds of business processes, which increases the complexity of checking whether all of them are compliant when one regulatory requirement changes. Raduescu, Tan, Jayaganesh, Bandara, zur Muehlen, and Lippe (2006), for example, reported on landscapes of over 1,800 business processes.

Considering this environment, compliance experts, who are responsible for the legal checking of new and changed business processes, need automation support for compliance-checking. As companies increasingly make use of business 
process models - graph-based formal business process description techniques like Event-driven Process Chains (EPCs) (Keller, Nüttgens, and Scheer 1992), Petri Nets (Peterson 1977) or the Business Process Model and Notation (BPMN) (Object Management Group 2011) - in order to design and document their business processes, Information Systems (IS) research reacts to this requirement with the development of (partly) automated model-based compliance-checking approaches and tools. The idea is to identify potential compliance violations in business processes by looking at the models describing them. Compliance-checking approaches have in common that they define compliance rule patterns, such as "activity A must be executed before activity B is executed" and apply them to a set of business process models to determine whether or not the process complies with the underlying rule. In real-world scenarios, such compliance-checking approaches are faced with two major challenges: First, a large number of conceptual modeling techniques exist and are used in practical environments (Davis, Green, Rosemann, Indulska, and Gallo 2006; zur Muehlen, Indulska, and Kamp 2007; zur Muehlen and Recker 2008). In effect, a compliance-checking approach should not be restricted to a distinct modeling technique to allow widespread application by companies. Second, regulations and compliance rules might be complex. Such complex regulations (e.g., escalation procedures, which include loops of business process activities combined with several alternative paths and different organizational units with different competencies) are, for instance, directed through the German risk management requirements (Gerstlberger, Kreuzkamp, Harland, and Altholz 2010). Hence, compliance-checking approaches should support the definition of such rules and their application to process models.

In practice, existing compliance-checking approaches have rarely been applied thus far. We assume that this is due to a very close focus of existing approaches - either on specific modeling techniques or on a very restricted set of possible rules to be checked. We argue that such a close focus could hinder companies from applying these approaches, when the modeling technique applied by the company does not fit the business process compliance-checking approach or the rules to be checked by a company cannot be addressed by the approach. Therefore, the purpose of this literature review is to analyze existing business process compliance-checking approaches according to (1) their applicability to arbitrary modeling techniques and (2) their ability to address a preferably wide range of possible compliance rules. Furthermore, to address the problem of applicability in practice, we (3) analyze the approaches according to their evaluation.

The reminder of the paper is structured as follows: We first describe the theoretical foundations and argue for the relevance of generalizability in compliance-checking approaches. Based on the theoretical findings, we briefly express the review criteria in the following section. After that, we explain the literature review search strategy, before we identify existing approaches on business-process compliance checking. These approaches are discussed regarding their generalizability. Based on this discussion, we identify research gaps and propose a research roadmap based on the findings of the literature review. A conclusion with contributions for research and practice finishes the paper.

\section{Theoretical Background and Analysis Criteria}

\subsection{Business Process Compliance Management}

In order to define the term business process compliance management, it is reasonable to understand Business Process Management (BPM) in general. Two perspectives on BPM have been established in the past: the IT-focused perspective and a holistic management perspective. While the IT-focused definition refers to business process automation (Harmon 2003: 255), the holistic management perspective focuses on analyzing and improving processes as a new way of organizational management (DeToro and McCabe 1997; Elzinga, Horak, Lee, and Bruner 1995; Zairi 1997). Besides the trend towards BPM, business process reengineering (BPR), which is defined as “... the fundamental rethinking and radical redesign of business processes to achieve dramatic improvements in critical contemporary measures of performance, such as cost, quality, service, and speed" (Hammer and Champy 1993), received a 
great deal of attention in IS research (i.e. Davenport and Stoddard 1994; Grant 2002). Nowadays, organizations are faced with a steady increase of both business processes complexity and regulations. Business processes need to follow regulations, which by their nature change very often. Thus, BPM and BPR are being forced more and more to react to and consider these regulatory requirements when business processes are managed or when processes must be redesigned fundamentally.

According to El Kharbili, Stein, Markovic, and Pulvermueller (2008), regulatory compliance consists of measures and directives, which are implemented by policies, internal controls and procedures and which are modeled for business processes. We adopt this view on regulatory compliance and combine it with the holistic management perspective on BPM in order to define business process compliance management (BPCM) as follows: BPCM is the steady modeling, refinement, and analysis of business processes regarding the fulfillment of regulatory compliance. Types of Compliance Rules

El Kharbili, Stein, Markovic, and Pulvermueller (2008) identified three classes of compliance rules: Regulations, IT security standards, and quality standards. One of the most prominent examples for regulations is the Sarbanes-Oxley Act (SOX), which is a major regulation for investor protection in the United States. Its section 404 (Definition of Internal Controls over Financial Reporting) in particular is one of the most strongly regarded sections due to its impact on IS academia. Other regulations like IT security standards (i.e., ISO/IEC 27002:2005) and quality standards like ISO 20000 further increase the number of relevant compliance requirements.

In order to enable an automated compliance checking, it is necessary that, besides a formal representation of process models, compliance requirements exist in an analyzable format. A formalized compliance requirement is a structural pattern (Ghose and Koliadis 2007), which defines how the structure of a subsection of a process model has to look like in order to comply with the underlying rule.

Compliance-checking approaches differ in the complexity of compliance rules they are able to support. The following categorization of compliance rule patterns was derived from the literature analysis, showing that compliance-checking approaches support different kinds of compliance rules. As any process model can be interpreted as a graph, we classify this complexity according to the properties of different, generally accepted types of graphs. A compliance pattern that, for example, only depicts a temporal or linear rule (like, e.g., "activity A must be executed before activity B starts") represents one of the simplest graph structures, namely a path (Diestel 2010). Therefore, we classify compliance patterns corresponding with a path as simple compliance patterns. More sophisticated compliance rules require considering resource-related issues additionally and include, for instance, organizational requirements. A corresponding compliance rule of such medium complexity is, for example, the separation of duties. It requires two succeeding activities to be executed by different persons. The structure of such compliance rules corresponds with the medium complex graph structure of a tree (Diestel 2010). Therefore, we classify compliance patterns corresponding with a tree as compliance patterns with a medium complexity.

Complex compliance rules may incorporate graph structures that underlie no structural restrictions. They represent, for instance, particular loops as an effect of decision alternatives and use information from other types of models like data diagrams, organization or architecture diagrams. One example for such a complex compliance pattern is the escalation procedure in credit-granting processes (Becker, Gruber, and Wohlert 2006: 452). A credit-granting decision needs to be forwarded to several decision instances and will finally be sent back to the initiating agent in order to grant the credit. Figure 1 contains a snapshot of such a complex compliance pattern.

Based on this categorization, a compliance-checking approach considering complex compliance rule patterns also supports medium complex and simple patterns. An approach supporting medium complex patterns also supports simple patterns. This correlation does not apply vice versa.

\section{Compliance Checking}

According to El Kharbili, De Medeiros, Stein, and van der Aalst (2008), compliance-checking approaches are separated into two categories: forward and backward compliance checking. Forward compliance-checking approaches aim to ensure process compliance either during process 
design-time or during process run-time. Designtime compliance checking means that processes are checked for compliance at the moment they are created and before they are executed - typically by analyzing their corresponding process models. Run-time compliance checking is done by monitoring processes while they are executed for instance by analyzing log files of supporting application software. Backward-compliance approaches detect whether compliance violations have already taken place in process instances. In this literature analysis, we focus on design-time compliance-checking approaches. All of these approaches have in common that they search for patterns in models either to show that these patterns occur or that they do not occur within the model.

\section{Figure 1: Complex Compliance Rule}

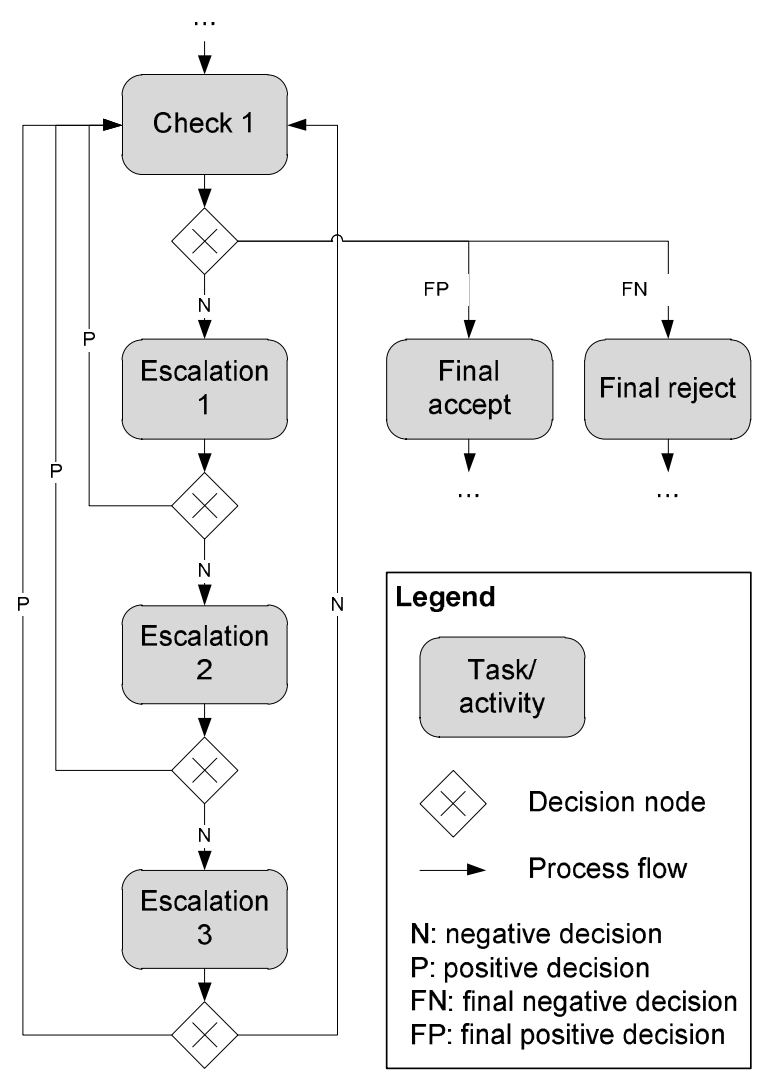

Figure 2 contains an example of a pattern search for the fulfillment of the four-eye principle, where an employee responsible for the execution of a business activity must be different from an em- ployee responsible for the execution of a successive activity.

Figure 2: Pattern search example

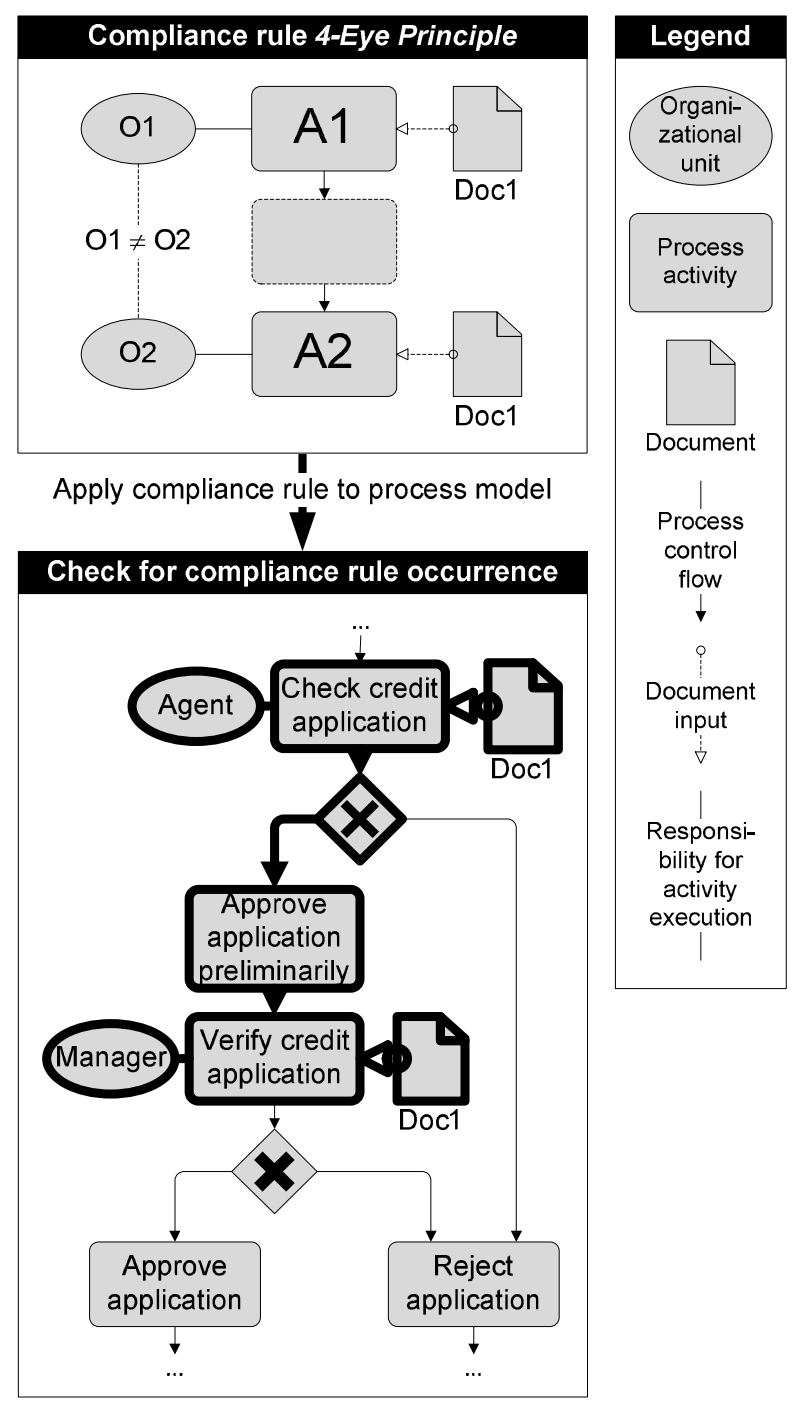

\subsection{Generalizability}

Detecting compliance violations in process models in the way shown above is only valuable for industry if corresponding compliance-checking approaches are applicable for a preferably high number of users/companies. Therefore, generalizability of corresponding approaches is of high importance. In their paper about Generalizability in Information Systems Research, Lee and Baskerville (2003) wrote about the importance of generalizability of IS research results. The authors stated that "the generalizability of a theory to a description of the results that the practitioner 
would observe if he were to use the theory in a new setting [...] is arguably the most important form of generalizability in business-school research". From a design science perspective, Hevner, March, Park, and Ram (2004) stated that "Design-science research holds the potential for three types of research contributions based on the novelty, generalizability, and significance of the designed artifact." Generalizability is therefore one essential goal of IS research, which brings us to the question of whether available compliancechecking approaches fulfill this essential requirement.

\subsection{Analysis Criteria}

Based on the identified generalizability requirement, we ask for the generalizability of compliance-checking approaches. Currently, a lot of different business process modeling techniques exist, which are quite popular (Recker, Rosemann, Indulska, and Green 2009). In addition, organizations adapt and extend these techniques in order to fulfill individual needs.

Considering generalizability in business process compliance checking leads to the question of whether existing compliance-checking approaches enable a general check of process models, regardless of which modeling technique they belong to. The modeling technique generalizability of an approach is defined as its capability to take models of different modeling techniques as inputs. An approach has a high modeling technique generalizability, when it is not restricted to a single modeling technique such as BPMN, but can be applied to any technique. If users are already adapted to a certain modeling technique, it is less likely that they will adapt a new or changed modeling technique to run compliance analyses. Since user acceptance is an important issue in IS research (Ginzberg 1981; Lucas Jr. 1975; Swanson 1987), the support of different modeling techniques is essential for the acceptance of a compliancechecking approach. Moreover, changing an established modeling technique of a company maintaining a large amount of models may lead to additional costs.

Like modeling technique generalizability, we further ask for the general applicability of compliance-checking approaches regarding all kinds of compliance rules. The compliance rule generalizability of an approach describes the capabilities to support modeling compliance requirements, which can be used as searchable process patterns. Narrow rule generalizability restricts modeling and checking of simple compliance patterns and thus supports only linear control flow rules. $\mathrm{Me}$ dium generalizability considers modeling and checking of compliance patterns of medium complexity and thus supports additional process annotations (such as resources and organizational units). An approach incorporating broad generalizability considers any kind of compliance rules, meaning even complex compliance patterns. In particular complex compliance rules, like rules that result in process flow circles and cross-references to other model types (e.g., organizational models), are one requirement to fulfill a broad level of generalizability.

Besides generalizability, we analyze the prototypical and real-world evaluation and check whether current approaches have been applied in a practical environment and what experiences the authors gained. Two reasons motivate this criterion: First, since "evaluation includes the integration of the artifact within the technical infrastructure of the business" (Hevner, March, Park, and Ram 2004), it is essential to investigate whether existing compliance-checking approaches have been evaluated in both experimental settings and business environments. Second, as searching for patterns in business process models equals the graph pattern matching problem, which has an exponential computational complexity (Ullmann 1976), it is important to see how efficient compliance-checking approaches are in real-world scenarios. To create compliance model-checking approaches that should be applicable to realistic large-scale models, "performance tuning and improvement of model checking is a critical research area" (Liu, Müller, and Xu 2007). We analyze evaluation with regard to three levels: The lowest level is characterized by the absence of evaluation or the limitation of the evaluation to a comparison to related work. The second level comprises approaches that include the implementation of business process compliance checking as a prototypical software tool, proving applicability and/or performance. Finally, at the most advanced level of evaluation, researchers evaluate their approach against the real-world problem in case studies, action research, etc. 


\section{Search Strategy}

In order to provide an overview of existing literature on model-based process compliance checking, we applied the approach suggested by Webster and Watson (2002) and vom Brocke, Simons, Niehaves, Riemer, Plattfaut, and Cleven (2009). We first defined keywords and queried journal databases. Second, we analyzed the citations of the found articles in order to perform a forward search. Third, we analyzed the references to the articles in order to conduct a backward search.

Our literature review focuses on research outcomes in the area of (conceptual) model checking in general and design-time compliance checking in particular; run-time and backward-compliance approaches are beyond the scope of this paper (for run-time and backward compliance see El Kharbili, De Medeiros, Stein, and van der Aalst 2008). Reviews of literature on compliance checking were already conducted by Awad (2010: 23) and El Kharbili, De Medeiros, Stein, and van der Aalst (2008). These literature reviews differ in two essential issues from the review at hand: First, the authors did not analyze the modeling technique and compliance rule-related generalizability of approaches. They rather provided a general overview. As discussed in section two, generalizability is one major requirement for all IS approaches. Without a general applicability these approaches will not be applicable in different scenarios. Second, neither literature review focuses on prototypical or real-world evaluation. Furthermore, due to the dynamic developments within the field, it can be expected that new approaches were published since the review of Awad (2010) that includes articles that were published up to 2009.

As literature sources for the analysis, we selected all journals from the AIS Senior Scholars' Basket, all journals and conference proceedings ranked A-C in the VHB JourQual 2.0 ranking (Schrader and Hennig-Thurau 2009) as well as the top 50 computer-science-related journals of the CORE ranking (http://www.gianvecchio.com/tier-jnlfinal2008.html). The combined rankings result in a list of 87 journals and conference proceedings which we provide in Appendix A. The temporal search scope for the keyword search was limited to publications between 2000 and 2011 (other search scopes are mentioned explicitly in Appendix A). We used a two-step keyword search, one search for more IS-related articles and one search for more computer-science-related articles. The IS related keywords are "process compliance", "workflow compliance", "workflow verification", and "process verification". As a more computerscience-related keyword, we use the term "model checking". We split our results into these two categories in order to provide an insight into the hit distribution among these keywords. It reveals that most model-checking articles focus on decision, software or system models. Process or workflow models are less regarded from articles that match this keyword search. As not all relevant articles upon a subject can be identified by searching within the limited scope of high-ranked journals and conference proceedings with a limited set of keywords, we performed a forward and backward search.

For the identification of referencing articles we used Google Scholar. As suggested by Levy and Ellis (2006), we considered the references of articles identified by backward reference search for another level of backward reference search. Both forward and backward search were not restricted to the list of mentioned (top) journals and conferences. The keyword search resulted in 113 articles for the compliance and verification search terms and in 675 hits for the keyword "model checking". From these articles, 10 from compliance and verification search and 13 from the model-checking search (three articles are duplicates) were selected based on a review of their abstracts for a detailed full-text review. The backward search resulted in 14 additional articles that were considered as relevant; the forward search revealed 21 additional articles. Articles focusing on runtime compliance monitoring (e.g., Namiri and Stojanovic 2007) or ex-post compliance auditing (e.g., Orriëns and Yang 2005) were omitted from further analysis, as they go beyond the scope of this paper. Furthermore, articles discussing abstract compliance management frameworks without concrete solutions for actual compliance checking were excluded as well as articles that simply provide an overview of existing approaches (e.g., Abdullah, Sadiq, and Indulska 2010). Hence, the following analysis considers only publications that focus on (mostly compliance-related) business process model checking, in total 48 
articles. However, in several cases more than one article covers the same approach and its improvement. Altogether, 26 different approaches could be identified in this way.

\section{Identified Approaches}

In the following, we present the set of articles that resulted from the literature search. We strongly focus on the criteria modeling technique generalizability, compliance rule generalizability and evaluation. All results are summarized in Table 1.

\subsection{Modeling Technique Generalizability} Analyzing the approaches regarding their modeling technique generalizability, it turns out that eight out of 26 approaches focus on the application of BPMN, namely Goedertier and Vanthienen (2006), Awad, Decker, and Weske (2008) and its successors, Ghose and Koliadis (2007), Schleicher, Anstett, Leymann, and Schumm (2010), Arbab, Kokash, and Meng (2009) and its successors, Accorsi, Lowis, and Sato (2011) as well as Wolter and Meinel (2010), and Mueller (2010). Besides BPMN, five approaches (in seven articles) use activity diagrams of the Unified Modeling Language (UML) (Object Management Group 2005) (Eshuis 2006; Eshuis and Wieringa 2004; Foerster, Engels, and Schattkowsky 2005; Foerster, Engels, Schattkowsky, and Van Der Straeten 2007; Khaluf, Gerth, and Engels 2011; Kuester, Ryndina, and Gall 2007; Kokash and Arbab 2009). In addition, seven approaches use the Business Process Execution Language (BPEL) or its successor (Organization for the Advancement of Structured Information Standards 2007) as their major application area for compliance checking (Arbab, Kokash, and Meng 2009; Hinz, Schmidt, and Stahl 2005; Liu, Müller, and Xu 2007; Lohmann and Wolf 2010; Monakova, Kopp, Leymann, Moser, and Schäfers 2009; Schleicher, Anstett, Leymann, and Schumm 2010; Xiangpeng, Cerone, and Krishnan 2006). The approach of Governatori, Milosevic, and Sadiq (2006) and its successors focus on graph and netbased techniques. Since each process model can be interpreted as a graph, we evaluate this approach with a high generalizability. Approaches that focus on process modeling but are independent of a specific modeling technique are Damaggio, Deutsch, Hull, and Vianu (2011), Soffer and
Wand (2004). The approach of Arbab, Kokash, and Meng (2009) supports a transformation from other modeling techniques like BPMN and BPEL into their own modeling technique, called Reo. However, an individual transformation is necessary, which does not fully satisfy the modeling technique generalizability criterion. The approaches of Sadiq, Governatori, and Namiri (2007) and Kumar and Liu (2008) follow a similar strategy. In contrast, the approaches from Ly, Rinderle-Ma, and Dadam (2006) and its successors fully satisfy the criterion as they are part of the approaches that explicitly state their "[independence] from the underlying process meta model" (Ly, Rinderle-Ma, and Dadam 2006: 195). Other approaches, like the one from Woerzberger, Kurpick, and Heer (2008a, 2008b) focus on proprietary modeling techniques like the "simplified syntax Business Process Execution Language" (SimBPEL).

\subsection{Compliance Rule Generalizability}

In order to judge compliance rule generalizability, we separated compliance patterns into three categories like already shown above: simple patterns, patterns of medium complexity and complex patterns. All approaches support the search for simple patterns. Nevertheless, there are three approaches which do not focus on control flows as simple patterns. Rather they shed light on one particular feature of control flow patterns. Kumar and Liu (2008) focused on organization-related compliance rules that prescribe who executes activities, sub-processes and processes. Accorsi, Lowis, and Sato (2011) developed a Petri-netbased approach to verify cloud-based workflows with a focus on data protection patterns. Further, the approach of Wolter, Miseldine, and Meinel (2009) as well as Wolter and Meinel (2010) allows for specifying hierarchical relations between organizational entities and the inheritance of authority within these hierarchies. Compliance rules can consider business object properties and simple control flow checks. Thus, this approach focuses on organizational issues in pattern design and does also not fully meet the control flow generalizability criterion.

Six approaches fully support the identification of all types of control flow annotations and thus support patterns of medium complexity (Gover- 


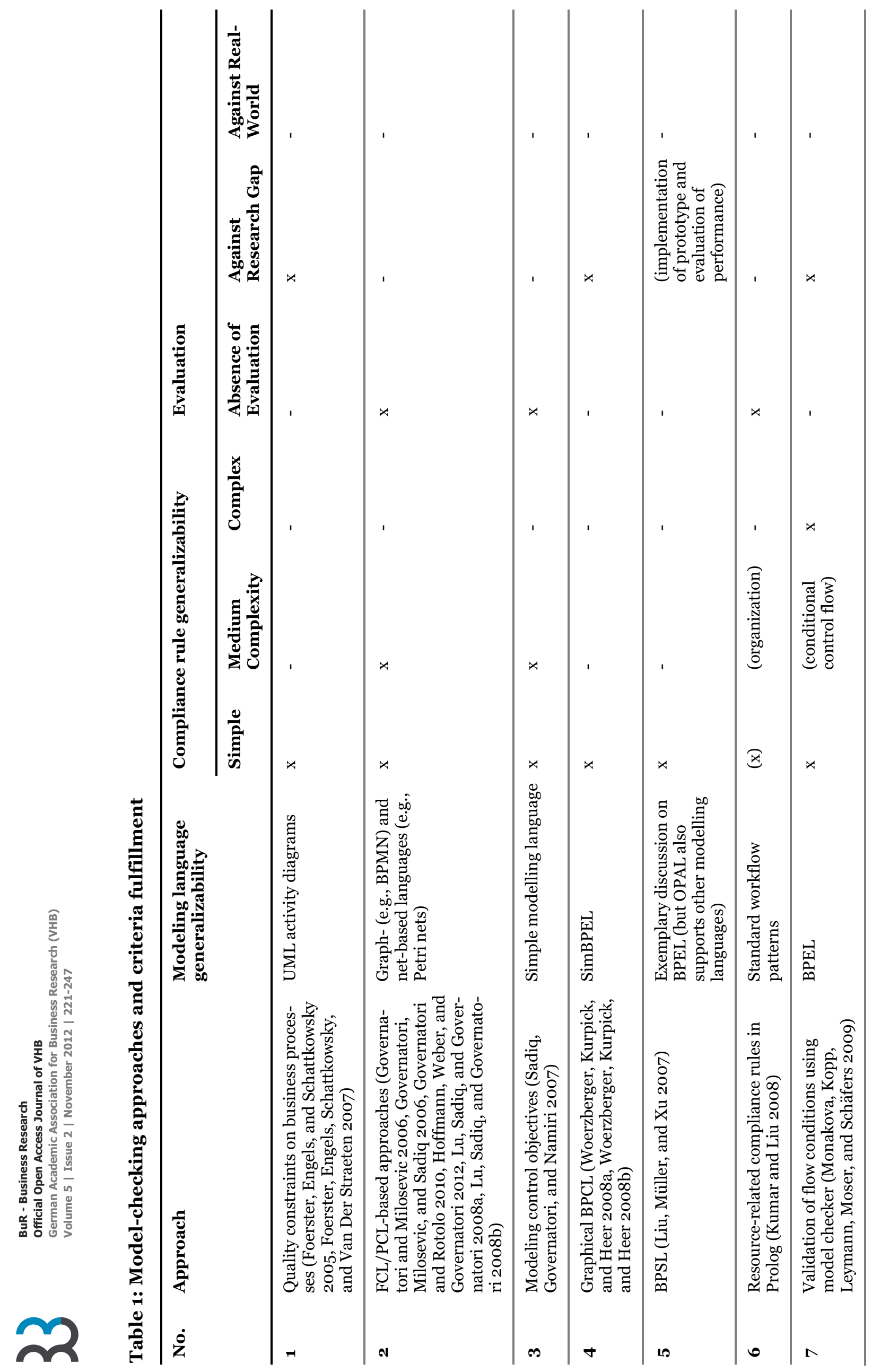




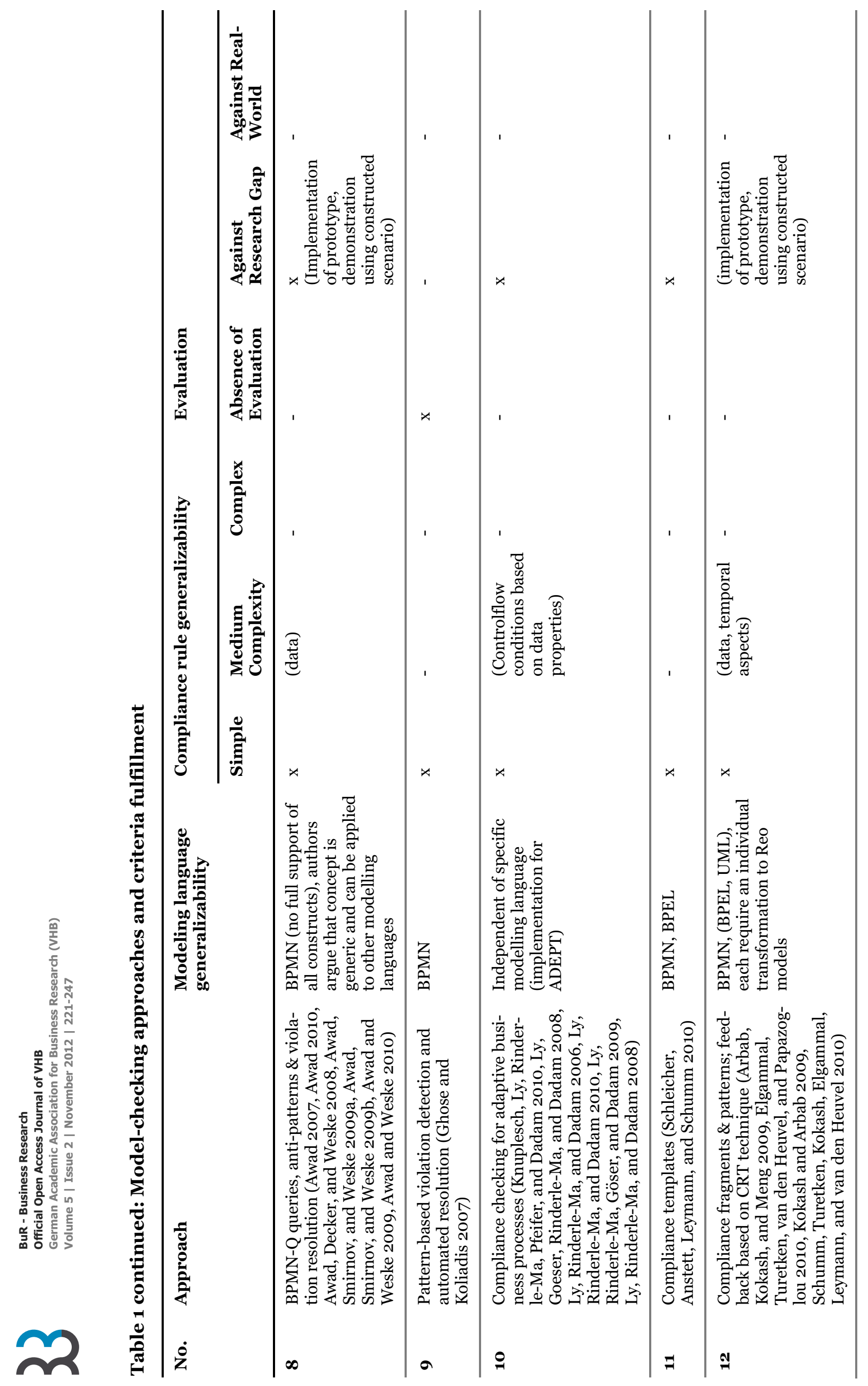




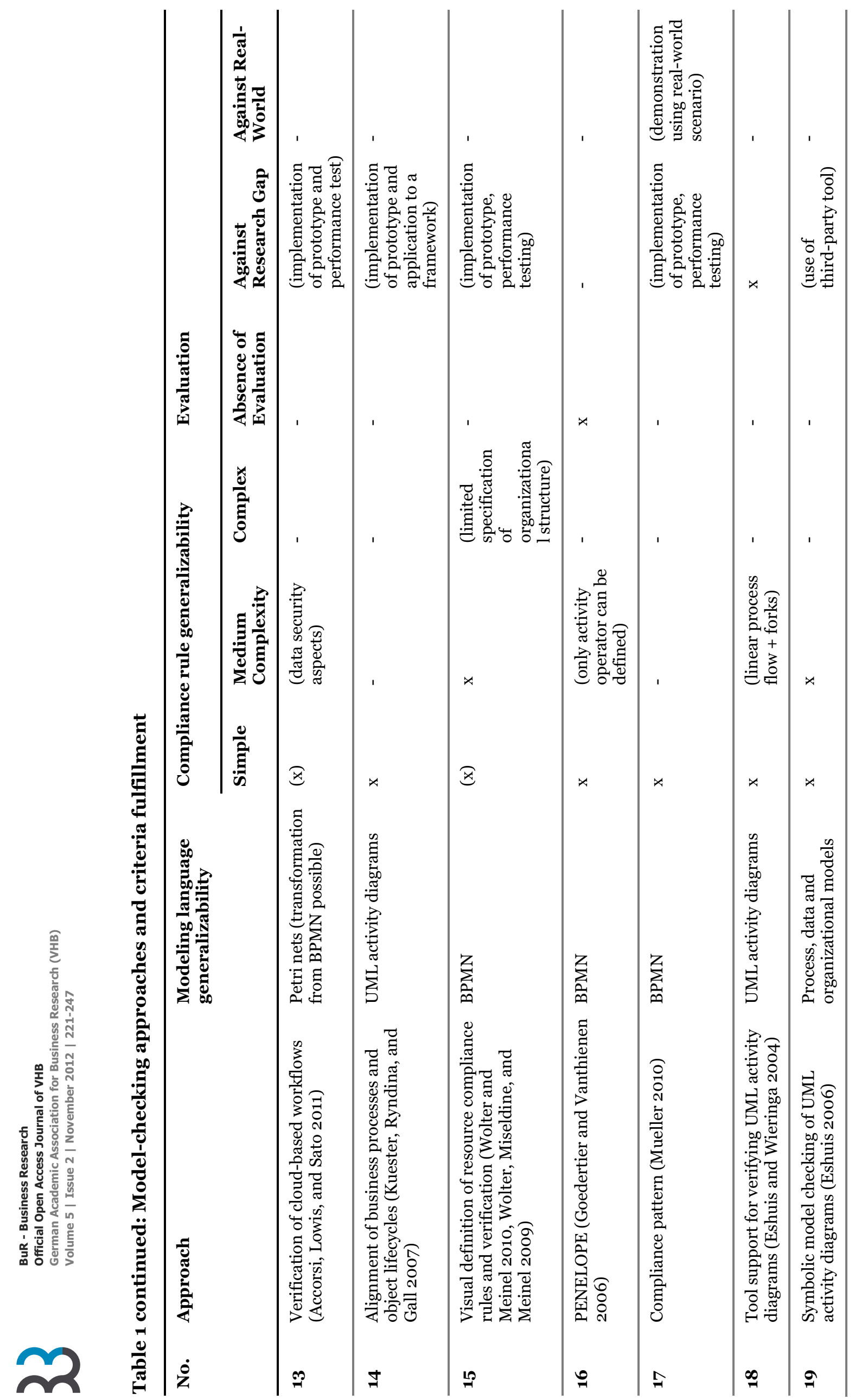




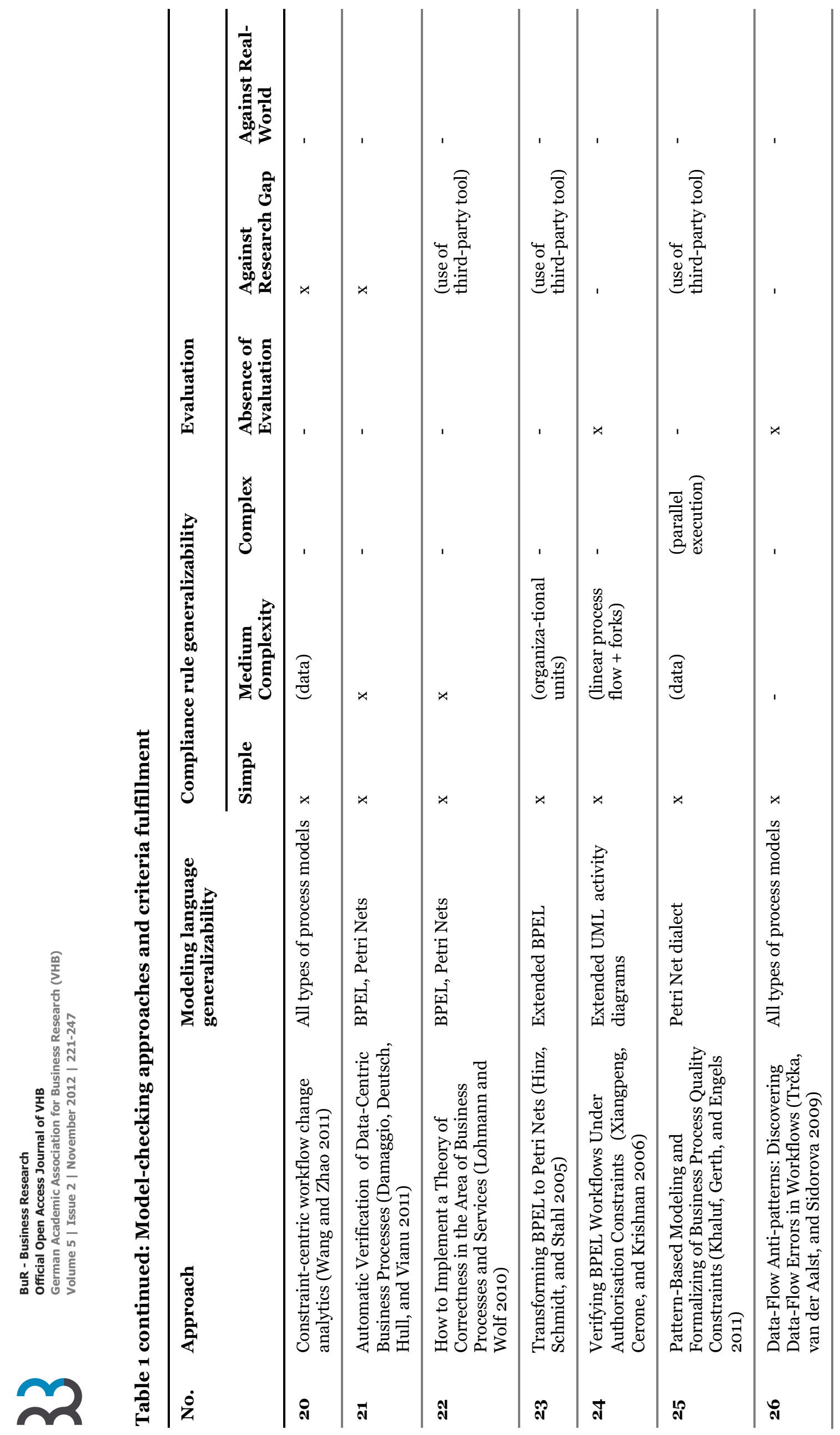


natori and Milosevic 2006; Hinz, Schmidt, and Stahl 2005; Lohmann and Wolf 2010; Sadiq, Governatori, and Namiri 2007; Wang and Zhao 2011; Wolter and Meinel 2010). All other approaches have a limited ability to define and search for patterns of medium complexity. Two approaches explicitly mentioned the ability to handle organizational units (Kumar and Liu 2008; Xiangpeng, Cerone, and Krishnan 2006). The approaches of Awad (2007), Arbab, Kokash, and Meng (2009), Damaggio, Deutsch, Hull, and Vianu (2011), Trčka, van der Aalst, and Sidorova (2009), and Ly, Rinderle-Ma, and Dadam (2006) as well as their successors handle data objects. The approach of Accorsi, Lowis, and Sato (2011) focuses on data security annotations, while the PENELOPE approach (Goedertier and Vanthienen 2006) supports the definition and check of activity operators. Two approaches could be identified that provided pattern recognition based on slightly more complex control flows than linear ones, including control flow forks (Eshuis 2006; Khaluf, Gerth, and Engels 2011). Monakova, Kopp, Leymann, Moser, and Schäfers (2009) as well as Knuplesch, Ly, Rinderle-Ma, Pfeifer, and Dadam (2010) enable the definition of conditional control flows. They provided additional compliance checks beyond simple control flow patterns. Similarly, Trčka, van der Aalst, and Sidorova (2009) allow for checking parallel process control flows.

Regarding the ability to define and search for complex compliance rules, for instance the specification of loops and integration of model elements that appear in other information models, only one approach could be identified that supports this feature. The approach of Monakova, Kopp, Leymann, Moser, and Schäfers (2009) "considers the dependency between control flow and data flow" and the research group investigates "possibilities to handle the loop constructs" (Monakova, Kopp, Leymann, Moser, and Schäfers 2009: 92). Moreover, Eshuis (2006) explicitly requires "that the activity diagram [must] not contain self-loops" (Eshuis 2006: 19). Wolter, Miseldine, and Meinel (2009) considered organizational units in their patterns, which is a first indication that the approach enables the definition of and search for any complex regulation pattern. Nevertheless, a detailed discussion about the compliance rule generalizability of their ap- proach remains open. All approaches, which we did not explicitly name in this subsection, are restricted to simple compliance patterns.

\subsection{Prototypical and Real-world Evaluation}

Altogether, 19 approaches were implemented as research prototypes or make use of a third-party tool in order to prove their applicability. Four of them (Accorsi, Lowis, and Sato 2011; Liu, Müller, and Xu 2007; Mueller 2010; Wolter and Meinel 2010) consider performance evaluation. Liu, Müller, and $\mathrm{Xu}$ (2007) recognized that compliance pattern search might be a performance-critical task. Thus, they improved the performance of their approach by applying state space reduction and controlled state space search using business patterns. By using this performance optimization, they reduced search times for simple compliance rules of at least 50 percent. Wolter, Miseldine, and Meinel (2009) measured the computation time for four different test cases. They obtained computation times between 0.01 and 0.33 seconds per case setting and tested the scalability of their approach. In his application scenario, Mueller (2010) applied several compliance patterns to process models of an aircraft maintenance firm and measured the time to compute the verification process. The approach of Eshuis (2006) and Eshuis and Wieringa (2004) used the model checker software NuSMV (Cimatti, Clarke, Giunchiglia, Giunchiglia, Pistore, Roveri, Sebastiani, and Tacchella 2002) in order to prove their concepts. Wang and Zhao (2011) showed how their approach can be implemented using different model-checking engines, provided by the OpenRulesBench platform (http://rulebench.projects. semwebcentral.org). A similar evaluation strategy was followed by Trčka, van der Aalst, and Sidorova (2009), who used different Petri-net-based model checkers. Hinz, Schmidt, and Stahl (2005) proposed a model transformation mechanism that makes models suitable as input for the LoLA model checker (Schmidt 2000). Lohmann and Wolf (2010) used the same tool. Xiangpeng, Cerone, and Krishnan (2006) used the model checker SAL (http://sal.csl.sri.com) to evaluate their approach.

Two other approaches (Arbab, Kokash, and Meng 2009; Awad 2007) used an artificial scenario in order to verify the applicability of their approach. 
Awad and Weske (2010) applied their compliance-checking approach to a compliance example from the banking sector. They provided a process model for the opening of a bank account. They successfully demonstrated the search of a compliance pattern and three anti-patterns. All applied patterns are simple patterns. The demonstration case of approach No. 12 is also a banking scenario (Schumm, Turetken, Kokash, Elgammal, Leymann, and van den Heuvel 2010). The authors used the loan origination process and represent the process by using BPMN. Three control flow compliance patterns are successfully applied to this process model. The applicability of the approach from Kuester, Ryndina, and Gall (2007) is demonstrated by its application to a process framework. Kuester, Ryndina, and Gall (2007) used the IBM Insurance Application Architecture and focused on the object life-cycle conformance of claim-handling processes.

Regarding real-world evaluation, only one approach fulfills this criterion. Mueller (2010) provided an evaluation using a real-world aircraft maintenance case. The compliance patterns are partly derived from requirements from the Federal Office of Civil Aeronautics. Nevertheless, an acceptance and relevance evaluation of the presented approach remains open.

\section{Discussion}

\subsection{Findings}

Figure 3 presents an overview and classification of the identified approaches in the literature search. The classification is based on the criteria modeling technique generalizability and compliance rule generalizability (cp. section 2). The approaches can be identified by their number, which is also listed in Table 1.

For the classification, we refined the initial distinction of high and low modeling technique generalizability as well as the three levels of compliance rule generalizability. Approaches that are restricted to one modeling technique differ in their generalizability depending on the standardization of the modeling technique supported. The underlying rationale is that supporting BPMN will allow a large number of organizations to easily adopt the approach due to the prevalence of BPMN. For the differentiation of approaches based on the compliance rule generalizability dimension, we chose the number of different model elements supported within one level. Approaches that support resource and data rules besides basic control flow rules have a higher generalizability than such approaches that solely support resource rules. Finally, the different evaluation levels are indicated by different shapes: rectangles represent approaches without evaluation, circles represent approaches with applicability and/or performance evaluation and diamonds represent approaches with evaluation against real-world scenarios.

\section{Figure 3: Classification of compliance- checking approaches}

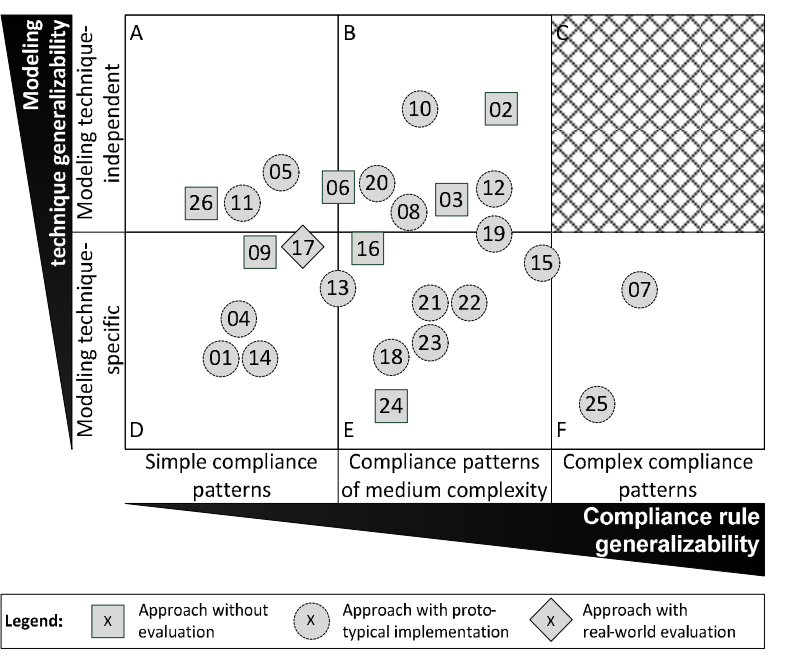

A substantial number of approaches lack both kinds of generalizability (areas A, D, E). Some of the reviewed approaches tightly integrate into existing concepts and technologies and use their specifics, preventing a transfer to other related concepts and technologies. For example, approaches using model analysis tools to evaluate compliance rules often require transformation methods to generate a formal model from a specific graph-based modeling notation. Considering the variety of common modeling techniques, including many self-developed techniques or techniques individually adapted from established modeling techniques, generalizability in terms of the supported modeling techniques is an important criterion for compliance-checking approaches in order to be widely applicable.

The focus of many reviewed compliance-checking approaches is either restricted to simple compli- 
ance patterns or to annotated information, such as business object properties and organizational entities (often triggered by IT security requirements relevant for Workflow Management Systems) - that is, patterns of medium complexity. Temporal rules are almost not present as they can only be verified at run-time (exceptions are Goedertier and Vanthienen 2006 and Kokash and Arbab 2009). Models that describe business object properties or resources apart from the control flow are not considered as additional sources for compliance checking. Considering approaches in area F, it is obvious that supporting any kind of compliance rule and just one single modeling technique does not fulfill the current requirements from practitioners. Therefore, further research is needed for approaches that first support any modeling technique and second can represent and handle any kind of compliance rule structure (Area C).

Additionally, the review reveals that the lack of real-world evaluation is a common problem in the field of business process compliance checking. Some of the approaches towards automated process compliance checking provide an evaluation against functionality. Most evaluations of this category are based on artificial scenarios consisting of a small set of business process models and a limited set of compliance rules that are used to demonstrate the functionality of a prototypical implementation (e.g., Kuester, Ryndina, and Gall 2007; Liu, Müller, and Xu 2007; Wolter and Meinel 2010). These evaluation methods can prove the applicability of an approach. However, they cannot assess its usefulness (Riege, Saat, and Bucher 2009). Only Mueller (2010) evaluated his approach against the real world in an extensive industry case study. But even this practical application does not contain an acceptance and relevance investigation. Besides this exception, the lack of real-world evaluation is surprising as most authors explicitly motivated their work with its relevance for practice. They discussed the usability of developed formal techniques for potential users (Wolter and Meinel 2010) or motivated their research by stating challenges for practice such as the complexity of manual compliance checking (e.g., Ly, Rinderle-Ma, Göser, and Dadam 2009) and the increasing regulatory pressure (e.g., Sadiq, Governatori, and Namiri 2007).
In addition to the predefined review criteria, some other findings are notable: First, many authors focused on issues of computational complexity and reduce the functionality of their approaches purposefully to increase their performance (e.g., Awad, Decker, and Weske 2008; Governatori, Milosevic, and Sadiq 2006). This highlights the computational challenges related to approaches operating on process model graphs. The computational complexity, in turn, increases the importance of evaluating compliance-checking approaches in a real-world context with sets of process models of realistic complexity (e.g., number of objects and relationships). Second, approaches that are based on compliance patterns use pattern definition techniques, which are structurally more similar to related compliance requirements than to business process models (Awad and Weske 2009; Elgammal, Turetken, Heuvel, and Papazoglou 2010; Mueller 2010). Third, in most of these approaches - except Mueller (2010) - predefined patterns are limited to the most frequent structures in compliance requirements. We think that this opens up major research potential, as it is not the most frequently occurring compliance rules that require the most support by compliance-checking approaches, but those that occur exceptionally. Complex structures that contain process loops or patterns that must be found across several models have not been considered yet. Fourth, the compliance check results, provided by most approaches that use model analysis tools, fail to support business and compliance experts in resolving compliance violations within processes. They include only exemplary violations (i.e., counterexamples) instead of an exhaustive feedback on all potential violations. Their compliance-checking algorithms terminate if they find a counterexample (Holzmann 1997). Fifth, we could observe that some of the approaches consider "semantics" in business process compliance checking (Ghose and Koliadis 2007; Namiri and Stojanovic 2007; El Kharbili, De Medeiros, Stein, and van der Aalst 2008; Ly, Goeser, Rinderle-Ma, and Dadam 2008). It is notable that, with the term "semantics", the authors of the analyzed papers meant specifically formal semantics. However, problems related to domain semantics, meaning possibly occurring ambiguities in the process models' labels (e.g., "invoice 
auditing" vs. "check bill"), are often neglected. Such ambiguities may lead to incorrect compliance-checking results, for instance when the terms used in a compliance rule pattern differ from those used in a process model, but were both intended to express the same issue - and vice versa. Hence, considering domain semantics in business process compliance-checking approaches opens up another important research field.

\subsection{Limitations}

Even if we analyzed a massive number of publications, we initially focused on publications in the area of top journals in IS and computer science. Thus, articles that appear in lower-ranked journals have not been considered here when they were not referencing articles in the initial search or have been cited in such articles. Furthermore, we focused on scientific and scholarly papers and did not include non-peer-reviewed or non-scientific approaches.

The results are summarized in a way that all approaches that belong to the same research tree are combined. We analyzed the research papers with regard to the stated criteria in the second main section of this article. If an approach supported one of the criteria but did not mention it in the paper, we rated the corresponding criterion as not fulfilled. Thus, approaches that support a certain criterion but do not consider it in the paper may be misevaluated.

Furthermore, pure run-time and backward compliance-checking approaches have not been considered in this literature review. Even if one of these approaches supported design-time compliance, it would have been excluded from this literature review. This was done because we aimed at representing the whole picture of approaches that are mainly investigated for design-time compliance purposes.

\section{Research Roadmap for Model- based Compliance Checking}

The findings of the literature review provide several research topics that should be addressed in the ongoing development of compliance-checking approaches. Based on theoretical thoughts about generalizability and evaluation of model-based compliance-checking approaches (cf. Section 2), we identified four research topics that constitute a research roadmap for IS researchers. These topics comply with the classification schema presented in Figure 3 and aim at pushing the state-of-theart of business process compliance-checking approaches to Sector $\mathrm{C}$, comprising evaluation. Consequently, we recommend to develop innovative BPCM approaches that:

- (1) enable model checking in any kind of graph-like model,

- (2) allow for defining and checking both simple and complex compliance patterns,

- (3) are evaluated against functionality, performance and utility.

Furthermore, we could identify the necessity to (4) assure semantic unambiguity in process models, since otherwise automatic compliance checking could lead to incorrect results.

As any business process compliance-checking approach is an IT artifact in the sense of the design science paradigm (like for instance proposed by Hevner, March, Park, and Ram 2004; March and Smith 1995; Österle, Becker, Frank, Hess, Karagiannis, Krcmar, Loos, Mertens, Oberweis, and Sinz 2010; Peffers, Tuunanen, Rothenberger, and Chatterjee 2007), we recommend using an according rigorous design science research procedure, especially because in such a research procedure, evaluation against functionality, performance and utility is mandatory. Design-oriented research procedures have in common that they require the construction of a so-called IT artifact, meaning a methodology, a procedure, or even a software tool that solves a business problem better than it was possible before.

First, it has to be proven that there is a problem at all and that a solution to that problem is desirable. Arguing for the general applicability of compliance-checking approaches, that initial research step is addressed in this paper.

Second, related work has to be analyzed and it has to be proven that the problem cannot be solved sufficiently by existing approaches. We address this second research step in this paper as well. Our literature review provides evidence that currently no approach exists, which enables compliance checking in terms of any modeling technique and any type of compliance rule.

Third, a solution approach is to be developed that overcomes the shortcomings of existing ones 
(from here, cf. recommendations of our research roadmap below). In order to design and develop a novel solution approach, which meets the elicited requirements and in accordance with Simon (1996: 111), we propose to use (especially for (1), (2), and (4)) a well-suited representation of the problem by creating conceptual models, mainly through concepts coming from the area of set theory (Cantor 1895) and graph theory (Diestel 2010: 2). The design and development phase delivers a concrete approach as well as its corresponding conceptual model.

Fourth, in order to demonstrate the applicability and sufficient performance of the new solution, it should be implemented as a demonstrator software tool. We suggest following Hevner, March, Park, and Ram (2004) and propose to initially demonstrate the applicability of the approach by its implementation and prototyping (Alavi 1984), comprising multiple iterations to improve the prototype according to its applicability and performance.

Fifth, to further prove the perceived usefulness of the (implemented) approach, it has to be applied in real-world scenarios, for instance in terms of a case study. We propose to use and adapt applicability and usefulness checks (Rosemann and Vessey 2008). All of these steps encompass the steady communication of research.

Develop approaches that enable model checking in any kind of graph-like models

The findings provide evidence that no existing approach enables a complete search on process models developed with arbitrary modeling techniques - combined with complex compliance patterns. Further research should focus on the development of generally applicable compliance checkers. Besides the support of arbitrary process modeling techniques, new compliance-checking approaches should be able to search for patterns in all kinds of graph-like models. In many cases, compliance requirements also affect IT resources (e.g., depicted by IS architecture diagrams), a company's organizational structure (e.g., depicted by organizational charts), or data (e.g., depicted by entity-relationship models). Thus, further development should focus on pattern matching solutions that can be applied to any kind of graphlike models. In addition to common concepts from conceptual modeling already mentioned above, we suggest taking into account previous work from graph theory, mainly on subgraph isomorphism and minor containment (e.g., Adler, Dorn, Fomin, Sau, and Thilikos 2010; Dorn 2010; Hajiaghayi and Nishimura 2007; Hicks 2004), an overview is given, e.g., by Conte, Foggia, Sansone, and Vento (2004), approaches on graph mining (an overview is given by Chakrabarti and Faloutsos 2006) as well as approaches coming from formal verification, especially model checking (e.g., Clarke, Grumberg, and Peled 2000: 35). As such approaches are not focused on compliance checking but address a similar problem and at the same time are more or less generically oriented, they could serve as a suitable basis for development.

Develop approaches that allow for defining and checking both simple and complex compliance patterns

The ongoing development of approaches should further be focused on the applicability of any type of compliance rule. The literature search provides evidence that currently there is no approach that supports any type of compliance rule while at the same time allows the usage of arbitrary modeling techniques. In particular, the search for patterns that contain control flow loops and process-overarching elements should be supported by future model-based compliance-checking approaches. Only when all types of patterns can be defined and searched, a sufficient solution, which is applicable in a real-world scenario, can be expected. In addition to common concepts from conceptual modeling already mentioned above, we suggest evaluating the same existing approaches from algorithmic graph theory already mentioned above and from computer science for the same reasons.

Evaluate approaches against functionality, performance and utility using prototypes

New approaches should be evaluated by using prototypes. The findings from the literature review show that ten approaches have not been evaluated in a prototypical setting. Thus, the authors could not prove the functionality of their approaches. A prototype is also a prerequisite for proving the generalizability of the approach. In order to address the support of several modeling techniques, a corresponding prototype should enable compliance pattern definitions and search in process models, created with different modeling techniques. 
Four approaches address the performance issue (No. 5, No. 13, No. 15, and No. 17), which in turn means that 22 approaches did not consider search performance explicitly. In the second main section, we already argue for the relevance of search performance. Present and future approaches should be evaluated regarding their performance and scalability. We recommend using a rigorous performance-measurement approach like for instance suggested by Georges, Buytaert, and Eeckhout (2007). Supporting arbitrary modeling techniques and arbitrary patterns makes it difficult to attain a high performance. To allow a high performance anyway, we suggest exploiting typical graph characteristics of conceptual models, especially planarity and bounded treewidth (Breuker, Dietrich, Püster, Steinhorst, Becker, and Delfmann 2012). According approaches that could be considered in this context were proposed, for example, by Hajiaghayi and Nishimura (2007) and Dorn (Dorn 2010).

Until now, we can just assume the practical utility of automated model-based compliance checking. 25 of 26 approaches have not been applied in a real-world setting. Many of them emphasize the relevance of automated compliance checking for organizations. In order to prove this assumption, a detailed investigation of acceptance, utility and relevance of compliance-checking approaches is necessary. We propose using applicability checks (Rosemann and Vessey 2008) and focus-group sessions (Stewart, Shamdasani, and Rook 2007: 37 ) in order to verify the applicability, utility and relevance of automated compliance-checking approaches in a real-world setting.

Develop a solution for semantically correct pattern definition and checking

As an additional issue that should be addressed by compliance-checking approaches, we identified the necessity to assure semantic unambiguity of process models and compliance patterns. For instance, a compliance pattern depicting the foureye-principle may contain a term called "check". Such a pattern would not be able to identify corresponding model sections when a modeler used the term "validate" instead or even mixed up "check" and "validate" in different areas of the process model. The same applies vice versa for the definition of patterns. This kind of problem can be overcome by using semantic enrichment of modeling techniques. The first steps regarding unambiguity in process models have been done, for instance, by Delfmann, Herwig, and Lis (2009) as well as Thomas and Fellmann (2009).

\section{Conclusion}

Defining and searching patterns that represent compliance requirements in business processes are supported by several approaches, which we reviewed and analyzed. Based on generalizability and evaluation concerns, we found that existing approaches focus more or less on special modeling techniques and a restricted set of compliance rules. We believe that this very narrow focus of most of the analyzed approaches hinders a widespread application in practice. This is what we actually observe today. Automated or at least semi-automated compliance-checking approaches that support decision makers in their day-to-day work are virtually not applied in practice.

The article contributes to both research and practice. From a scientific perspective, the literature review enables the identification of research gaps and provides new research directions in order to create and evaluate design-time compliancechecking approaches. Altogether, four research gaps have been identified: First, most approaches did not recognize the need for a generalizability of compliance checking. They are mainly focused on one particular modeling technique or one special scenario. Second, current research focuses on an excerpt of regulations and does not consider the whole bunch of regulation complexity. Complex checking routines like for escalation procedures (e.g., German minimum requirements for risk management, Section BTO 1.1) are not considered yet. Thus, not all regulations can be represented, which may lead to insufficient compliance checking results. Third, an appropriate evaluation is mostly missing. In particular, in complex realworld cases where hundreds of business processes, organizational units and resource elements need to be checked, performance becomes a critical requirement. Further research is needed to provide an insight into the performance of different approaches in different application settings. Furthermore, only one approach (Mueller 2010) has been evaluated comprehensively. An extensive evaluation is needed to prove the relevance and acceptance of business process compliance-checking approaches in a real-world scenario. Fourth, we could identify the need to as- 
sure semantic unambiguity of business process models to assure consistent compliance-checking results. Although compliance checking researchers are aware of this problem, a compliance-related solution to this problem is still lacking and opens potential for further research. In order to guide further research, we proposed a research roadmap, derived from the literature analysis.

From a practical perspective, the literature review enables a search for adoptable approaches for real-world projects. Since the level of regulation is increasing steadily, compliance experts are being forced more and more to find tools for managing regulations that affect business processes. This work is a step towards comprehensively informing compliance experts about appropriate approaches for their needs, and it points out new research directions in the area of business process compliance checking.

\section{Appendix: Keyword Search Results for Initial Search}

\begin{tabular}{|c|c|c|c|c|c|c|c|}
\hline \multirow[t]{2}{*}{ Journal } & \multirow[t]{2}{*}{ Database } & \multirow[t]{2}{*}{$\begin{array}{l}\text { Search } \\
\text { Fields }\end{array}$} & \multirow[t]{2}{*}{ Coverage } & \multicolumn{2}{|c|}{$\begin{array}{l}\text { Compliance / } \\
\text { Verification }\end{array}$} & \multicolumn{2}{|c|}{$\begin{array}{l}\text { Model } \\
\text { Checking }\end{array}$} \\
\hline & & & & 象 & 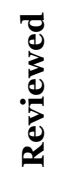 & $\sum^{2}$ & 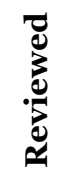 \\
\hline ACM Computing Reviews & $\begin{array}{l}\text { ACM Digital } \\
\text { Library }\end{array}$ & all & 2001-2011 & o & o & o & 0 \\
\hline ACM Computing Surveys & $\begin{array}{l}\text { ACM Digital } \\
\text { Library }\end{array}$ & all & 2001-2011 & 1 & o & 17 & o \\
\hline $\begin{array}{l}\text { ACM Journal of Experimental } \\
\text { Algorithmics }\end{array}$ & $\begin{array}{l}\text { ACM Digital } \\
\text { Library }\end{array}$ & all text & 2001-2011 & o & o & o & o \\
\hline ACM Transactions on Algorithms & $\begin{array}{l}\text { ACM Digital } \\
\text { Library }\end{array}$ & all text & 2001-2011 & o & o & 2 & o \\
\hline $\begin{array}{l}\text { ACM Transactions on Architecture } \\
\text { and Code Optimization }\end{array}$ & $\begin{array}{l}\text { ACM Digital } \\
\text { Library }\end{array}$ & all text & 2001-2011 & o & o & 1 & 0 \\
\hline $\begin{array}{l}\text { ACM Transactions on } \\
\text { Computational Logic }\end{array}$ & $\begin{array}{l}\text { ACM Digital } \\
\text { Library }\end{array}$ & all text & 2001-2011 & o & o & 95 & o \\
\hline $\begin{array}{l}\text { ACM Transactions on Computer } \\
\text { Human Interaction }\end{array}$ & $\begin{array}{l}\text { ACM Digital } \\
\text { Library }\end{array}$ & all & 2000-2010 & o & o & 1 & o \\
\hline $\begin{array}{l}\text { ACM Transactions on Computer } \\
\text { Systems }\end{array}$ & EbscoHost & all text & 2001-2011 & o & o & 6 & o \\
\hline $\begin{array}{l}\text { ACM Transactions on Database } \\
\text { Systems }\end{array}$ & $\begin{array}{l}\text { ACM Digital } \\
\text { Library }\end{array}$ & all & 2000-2011 & 1 & o & 4 & o \\
\hline ACM Transactions on Graphics & $\begin{array}{l}\text { ACM Digital } \\
\text { Library }\end{array}$ & all text & 2001-2011 & o & o & 1 & o \\
\hline $\begin{array}{l}\text { ACM Transactions on Information } \\
\text { Systems }\end{array}$ & $\begin{array}{l}\text { ACM Digital } \\
\text { Library }\end{array}$ & all & 2001-2010 & o & o & 2 & o \\
\hline $\begin{array}{l}\text { ACM Transactions on } \\
\text { Mathematical Software }\end{array}$ & EbscoHost & all text & 2001-2011 & $\mathrm{o}$ & o & $\mathrm{o}$ & o \\
\hline $\begin{array}{l}\text { ACM Transactions on Program- } \\
\text { ming Languages and Systems }\end{array}$ & EbscoHost & all text & 2001-2011 & 1 & o & 74 & o \\
\hline
\end{tabular}




\section{Appendix continued: Keyword Search Results for Initial Search}

\begin{tabular}{|c|c|c|c|c|c|c|c|}
\hline \multirow[t]{2}{*}{ Journal } & \multirow[t]{2}{*}{ Database } & \multirow[t]{2}{*}{$\begin{array}{l}\text { Search } \\
\text { Fields }\end{array}$} & \multirow[t]{2}{*}{ Coverage } & \multicolumn{2}{|c|}{$\begin{array}{l}\text { Compliance / } \\
\text { Verification }\end{array}$} & \multicolumn{2}{|c|}{$\begin{array}{l}\text { Model } \\
\text { Checking }\end{array}$} \\
\hline & & & & $\sum_{i=1}^{\infty}$ & 尊 & $\stackrel{2}{=}$ & ב⿱艹 \\
\hline $\begin{array}{l}\text { ACM Transactions on Software } \\
\text { Engineering and Methodology }\end{array}$ & $\begin{array}{l}\text { ACM Digital } \\
\text { Library }\end{array}$ & all text & 2001-2011 & o & o & 49 & 1 \\
\hline Algorithmica & SpringerLink & all text & 2001-2011 & 0 & o & 2 & $\mathrm{O}$ \\
\hline $\begin{array}{l}\text { Annual Review of Information } \\
\text { Science and Technology }\end{array}$ & $\begin{array}{l}\text { Wiley Online } \\
\text { Library }\end{array}$ & all text & 2001-2011 & o & o & o & 0 \\
\hline Artificial Intelligence & ScienceDirect & all & 2001-2011 & 2 & o & 80 & $\mathrm{O}$ \\
\hline $\begin{array}{l}\text { Australian Journal of Information } \\
\text { Systems }\end{array}$ & Journal website & all & 2001-2011 & o & o & o & 0 \\
\hline Communications of the ACM & $\begin{array}{l}\text { ACM Digital } \\
\text { Library }\end{array}$ & $\begin{array}{l}\text { title, } \\
\text { abstract, } \\
\text { review }\end{array}$ & 2001-2011 & 4 & $\mathrm{o}$ & 71 & $\mathrm{O}$ \\
\hline Communications of the AIS & AIS e-Library & $\begin{array}{l}\text { title, } \\
\text { abstract, } \\
\text { keywords, } \\
\text { subject area }\end{array}$ & 2001-2011 & 10 & o & 2 & 0 \\
\hline $\begin{array}{l}\text { Computer Supported Cooperative } \\
\text { Work }\end{array}$ & SpringerLink & all text & 2001-2011 & o & o & o & $\mathrm{O}$ \\
\hline $\begin{array}{l}\text { Computers and Operations } \\
\text { Research }\end{array}$ & ScienceDirect & all & 2001-2011 & o & o & 4 & 0 \\
\hline Data and Knowledge Engineering & ScienceDirect & all & 2001-2011 & 21 & 1 & 29 & $\mathrm{O}$ \\
\hline Decision Support Systems & ScienceDirect & all & 2001-2011 & 8 & o & 11 & 1 \\
\hline Electronic Markets & $\begin{array}{l}\text { Informa / } \\
\text { SpringerLink }\end{array}$ & all & 2001-2011 & o & o & o & 0 \\
\hline $\begin{array}{l}\text { Enterprise Modelling and Infor- } \\
\text { mation Systems Architectures }\end{array}$ & Journal website & title & $2005-2011$ & o & o & 1 & 0 \\
\hline $\begin{array}{l}\text { European Journal of Information } \\
\text { Systems }\end{array}$ & $\begin{array}{l}\text { Palgrave } \\
\text { Macmillan }\end{array}$ & all & 2001-2011 & o & o & o & o \\
\hline Evolutionary Computation & Journal website & & 2001-2011 & o & o & o & 0 \\
\hline Human-Computer Interaction & Journal website & & 2001-2011 & o & o & o & o \\
\hline IEEE Pervasive Computing & IEEE Xplore & all & 2001-2011 & o & o & o & 0 \\
\hline IEEE Software & IEEE Xplore & all & 2001-2011 & 7 & $\mathrm{O}$ & 3 & $\mathrm{O}$ \\
\hline IEEE Transactions on Computers & EbscoHost & all text & 2001-2011 & o & o & 13 & o \\
\hline $\begin{array}{l}\text { IEEE Transactions on Engineering } \\
\text { Management }\end{array}$ & IEEE Xplore & all & 2001-2011 & 3 & o & o & 0 \\
\hline
\end{tabular}




\section{Appendix continued: Keyword Search Results for Initial Search}

\begin{tabular}{|c|c|c|c|c|c|c|c|}
\hline \multirow[t]{2}{*}{ Journal } & \multirow[t]{2}{*}{ Database } & \multirow[t]{2}{*}{$\begin{array}{l}\text { Search } \\
\text { Fields }\end{array}$} & \multirow[t]{2}{*}{ Coverage } & \multicolumn{2}{|c|}{$\begin{array}{l}\text { Compliance / } \\
\text { Verification }\end{array}$} & \multicolumn{2}{|c|}{$\begin{array}{l}\text { Model } \\
\text { Checking }\end{array}$} \\
\hline & & & & $\stackrel{2}{20}$ & 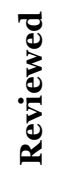 & $\sum_{0=1}^{\infty}$ & 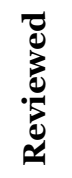 \\
\hline $\begin{array}{l}\text { IEEE Transactions on Fuzzy } \\
\text { Systems }\end{array}$ & IEEE Xplore & all text & 2001-2011 & 0 & o & 1 & o \\
\hline $\begin{array}{l}\text { IEEE Transactions on Image } \\
\text { Processing }\end{array}$ & EbscoHost & all text & 2001-2011 & o & o & o & 0 \\
\hline $\begin{array}{l}\text { IEEE Transactions on Information } \\
\text { Theory }\end{array}$ & EbscoHost & all text & 2001-2011 & o & o & o & o \\
\hline $\begin{array}{l}\text { IEEE Transactions on Parallel and } \\
\text { Distributed Systems }\end{array}$ & EbscoHost & all text & 2001-2011 & o & o & 2 & $\mathrm{O}$ \\
\hline $\begin{array}{l}\text { IEEE Transactions on Pattern } \\
\text { Analysis and Machine Intelligence }\end{array}$ & EbscoHost & all text & 2001-2011 & o & o & o & o \\
\hline $\begin{array}{l}\text { IEEE Transactions on Software } \\
\text { Engineering }\end{array}$ & EbscoHost & all text & 2001-2011 & o & $\mathrm{o}$ & 45 & 1 \\
\hline $\begin{array}{l}\text { IEEE-ACM Transactions on } \\
\text { Networking }\end{array}$ & IEEE Xplore & all text & 2001-2011 & o & o & o & o \\
\hline Information and Management & ScienceDirect & all & 2001-2011 & o & o & o & o \\
\hline Information and Organization & ScienceDirect & all & 2001-2011 & o & o & o & o \\
\hline $\begin{array}{l}\text { Information Research - An } \\
\text { International Electronic Journal }\end{array}$ & free e-journal & all text & 2001-2011 & o & o & o & $\mathrm{O}$ \\
\hline Information Systems & ScienceDirect & all & 2001-2011 & 6 & O & 12 & O \\
\hline $\begin{array}{l}\text { Information Systems and } \\
\text { eBusiness Management }\end{array}$ & SpringerLink & all & $2003-2011$ & o & o & 1 & 0 \\
\hline Information Systems Frontiers & SpringerLink & all & 2000-2011 & 7 & 2 & 5 & 1 \\
\hline Information Systems Journal & $\begin{array}{l}\text { Wiley Online } \\
\text { Library }\end{array}$ & all & 2000-2011 & o & o & o & $\mathrm{O}$ \\
\hline Information Systems Research & EBSCOhost & all & 2000-2011 & o & o & o & o \\
\hline INFORMS Journal on Computing & EBSCOhost & all & 2000-2011 & 0 & $\mathrm{O}$ & o & 0 \\
\hline $\begin{array}{l}\text { International Journal of Electronic } \\
\text { Commerce }\end{array}$ & EBSCOhost & all & 2000-2011 & 0 & 0 & o & 0 \\
\hline $\begin{array}{l}\text { International Journal of } \\
\text { Information Management }\end{array}$ & ScienceDirect & all & 2000-2011 & o & 0 & o & 0 \\
\hline $\begin{array}{l}\text { International Journal on Media } \\
\text { Management }\end{array}$ & EBSCOhost & all & 2000-2011 & o & o & o & 0 \\
\hline $\begin{array}{l}\text { International Journal on Very } \\
\text { Large Data Bases (VLDB) }\end{array}$ & SpringerLink & all text & 2001-2011 & o & o & o & o \\
\hline
\end{tabular}




\section{Appendix continued: Keyword Search Results for Initial Search}

\begin{tabular}{|c|c|c|c|c|c|c|c|}
\hline \multirow[t]{2}{*}{ Journal } & \multirow[t]{2}{*}{ Database } & \multirow[t]{2}{*}{$\begin{array}{l}\text { Search } \\
\text { Fields }\end{array}$} & \multirow[t]{2}{*}{ Coverage } & \multicolumn{2}{|c|}{$\begin{array}{l}\text { Compliance / } \\
\text { Verification }\end{array}$} & \multicolumn{2}{|c|}{$\begin{array}{l}\text { Model } \\
\text { Checking }\end{array}$} \\
\hline & & & & $\stackrel{n}{2}^{\infty}$ & 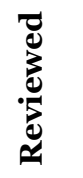 & $\stackrel{n}{=}$ & 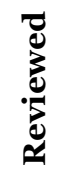 \\
\hline Journal of the AIS & AIS e-Library & $\begin{array}{l}\text { title, } \\
\text { abstract, } \\
\text { keywords, } \\
\text { subject area }\end{array}$ & 2000-2011 & 3 & o & o & o \\
\hline Journal of Computational Finance & Journal website & all & 2000-2011 & o & o & o & o \\
\hline $\begin{array}{l}\text { Journal of Computer and System } \\
\text { Sciences }\end{array}$ & ScienceDirect & all text & 2001-2011 & 3 & o & 33 & 0 \\
\hline Journal of Cryptology & SpringerLink & all text & 2001-2011 & o & o & o & 0 \\
\hline Journal of Documentation & $\begin{array}{l}\text { Emerald } \\
\text { Backfiles }\end{array}$ & all text & 2001-2011 & o & o & o & o \\
\hline Journal of Information Science & EbscoHost & all text & 2001-2011 & o & o & o & O \\
\hline $\begin{array}{l}\text { Journal of Information } \\
\text { Technology }\end{array}$ & Journal website & all & 2000-2011 & o & o & o & 0 \\
\hline $\begin{array}{l}\text { Journal of Management } \\
\text { Information Systems }\end{array}$ & EBSCOhost & all & 2000-2011 & o & o & o & 0 \\
\hline $\begin{array}{l}\text { Journal of Parallel and Distributed } \\
\text { Computing }\end{array}$ & ScienceDirect & all text & 2001-2011 & 1 & o & 7 & 0 \\
\hline $\begin{array}{l}\text { Journal of Strategic Information } \\
\text { Systems }\end{array}$ & ScienceDirect & all & 2000-2011 & o & o & o & 0 \\
\hline Journal of the ACM & $\begin{array}{l}\text { ACM Digital } \\
\text { Library }\end{array}$ & all & 2000-2011 & 1 & o & 24 & $\mathrm{O}$ \\
\hline $\begin{array}{l}\text { Journal of the American Society } \\
\text { for Information Science and } \\
\text { Technology }\end{array}$ & EbscoHost & all text & 2001-2011 & o & o & 1 & 0 \\
\hline Lecture Notes in Informatics & Google Scholar & all & 2001-2011 & o & o & 3 & $\mathrm{O}$ \\
\hline $\begin{array}{l}\text { Library \& Information Science } \\
\text { Research }\end{array}$ & ScienceDirect & all text & 2001-2011 & o & o & 1 & o \\
\hline Library Quarterly & EbscoHost & all text & 2001-2011 & o & $\mathrm{o}$ & o & $\mathrm{O}$ \\
\hline Library Trends & EbscoHost & all text & 2001-2011 & o & o & o & o \\
\hline Machine Learning & SpringerLink & all text & 2001-2011 & 0 & o & 4 & 0 \\
\hline Mathematical Programming & SpringerLink & all & 2000-2011 & 0 & o & o & o \\
\hline MIS Quarterly & EBSCOhost & all & 2000-2011 & o & o & o & o \\
\hline MIS Quarterly Executive & Journal website & & 2002-2011 & o & O & o & O \\
\hline
\end{tabular}




\section{Appendix continued: Keyword Search Results for Initial Search}

\begin{tabular}{|c|c|c|c|c|c|c|c|}
\hline \multirow[t]{2}{*}{ Journal } & \multirow[t]{2}{*}{ Database } & \multirow[t]{2}{*}{$\begin{array}{l}\text { Search } \\
\text { Fields }\end{array}$} & \multirow[t]{2}{*}{ Coverage } & \multicolumn{2}{|c|}{$\begin{array}{l}\text { Compliance / } \\
\text { Verification }\end{array}$} & \multicolumn{2}{|c|}{$\begin{array}{l}\text { Model } \\
\text { Checking }\end{array}$} \\
\hline & & & & $\stackrel{n}{=}$ & 恖 & $\stackrel{2}{=}$ & 尊 \\
\hline Neural Computation & EbscoHost & all text & 2001-2011 & o & O & 3 & O \\
\hline Omega & ScienceDirect & all & 2001-2011 & 1 & o & o & o \\
\hline $\begin{array}{l}\text { Proceedings of the Conference on } \\
\text { Advanced Information Systems } \\
\text { Engineering }\end{array}$ & SpringerLink & all & 2001-2011 & 7 & 1 & 18 & 3 \\
\hline $\begin{array}{l}\text { Proceedings of the Conference on } \\
\text { Very Large Data Bases }\end{array}$ & Journal website & title & 2001-2011 & o & o & o & o \\
\hline $\begin{array}{l}\text { Proceedings of the European Con- } \\
\text { ference on Information Systems }\end{array}$ & AIS e-Library & $\begin{array}{l}\text { title, } \\
\text { abstract, } \\
\text { keywords, } \\
\text { subject area }\end{array}$ & 2000-2010 & 1 & o & 2 & o \\
\hline $\begin{array}{l}\text { Proceedings of the International } \\
\text { Conference on Business Process } \\
\text { Management }\end{array}$ & SpringerLink & all text & 2001-2011 & 19 & 4 & 25 & 5 \\
\hline $\begin{array}{l}\text { Proceedings of the International } \\
\text { Conference on Conceptual } \\
\text { Modeling }\end{array}$ & SpringerLink & all text & 2000-2010 & 3 & 1 & 5 & 1 \\
\hline $\begin{array}{l}\text { Proceedings of the International } \\
\text { Conference on Information } \\
\text { Systems }\end{array}$ & AIS e-Library & $\begin{array}{l}\text { title, } \\
\text { abstract, } \\
\text { keywords, } \\
\text { subject area }\end{array}$ & 2000-2010 & o & o & 1 & 0 \\
\hline $\begin{array}{l}\text { Quantum Information \& } \\
\text { Computation }\end{array}$ & Google Scholar & all text & 2001-2011 & o & o & o & o \\
\hline School Library Media Research & Google Scholar & all text & 2001-2011 & o & o & o & $\mathrm{O}$ \\
\hline SIAM Journal on Computing & EBSCOhost & all text & 2000-2010 & o & o & 10 & o \\
\hline $\begin{array}{l}\text { Tagungsbände der } \\
\text { Wirtschaftsinformatik }\end{array}$ & AIS e-Library & $\begin{array}{l}\text { title, } \\
\text { abstract, } \\
\text { keywords, } \\
\text { subject area }\end{array}$ & 2001-2011 & 1 & 0 & 4 & 0 \\
\hline $\begin{array}{l}\text { The DATA BASE for Advances in } \\
\text { Information Systems }\end{array}$ & $\begin{array}{l}\text { ACM Digital } \\
\text { Library }\end{array}$ & $\begin{array}{l}\text { title, } \\
\text { abstract, } \\
\text { review }\end{array}$ & 2000-2011 & o & o & o & o \\
\hline $\begin{array}{l}\text { Wirtschaftsinformatik (Business \& } \\
\text { Information Systems Engineering) }\end{array}$ & SpringerLink & all text & 2006-2011 & 2 & 1 & o & o \\
\hline Total & & & & 113 & 10 & 675 & 13 \\
\hline
\end{tabular}




\section{Acknowledgements}

This paper was developed within the context of the research project "Business Process Compliance Management in Financial Industries (ProCom)", which is currently funded by the German Research Foundation (DFG, funding number: DE 1983/1-1).

\section{References}

Abdullah, Norris Syed, Shazia Sadiq, and Marta Indulska (2010): Emerging Challenges in Information Systems Research for Regulatory Compliance Management in: Barbara Pernici (ed.): Advanced Information Systems Engineering, Springer: Berlin et al., 251-265.

Accorsi, Rafael, Lutz Lowis, and Yoshinori Sato (2011): Automated Certification for Compliant Cloud-Based Business Processes, Business \& Information Systems Engineering, 3 (3): 145-154

Adler, Isolde, Frederic Dorn, Fedor V. Fomin, Ignasi Sau, and Dimitrios M. Thilikos (2010): Faster Parameterized Algorithms for Minor Containment, in: Haim Kaplan (ed.): Algorithm Theory: SWAT 2010, Springer: Berlin et al., 322333.

Alavi, Maryam (1984): An Assessment of the Prototyping Approach to Information Systems Development, Communications of the ACM, 27 (6): 556-563.

Arbab, Farhad, Natallia Kokash, and Sun Meng (2009): Towards Using Reo for Compliance-Aware Business Process Modeling, in: Margaria Tiziana and Steffen Bernhard (eds.): Leveraging Applications of Formal Methods, Verification and Validation, Springer: Berlin et al., 108-123.

Awad, Ahmed (2007): BPMN-Q: A Language to Query Business Processes, in: Manfred Reichert, Stefan Strecker, and Klaus Turowski (eds.): Enterprise Modelling and Information Systems Architectures: Concepts and Applications, Gesellschaft für Informatik: Bonn, 115-128.

Awad, Ahmed (2010): A Compliance Management Framework for Business Process Models, Dissertation, University of Potsdam: Potsdam.

Awad, Ahmed, Gero Decker, and Mathias Weske (2008): Efficient Compliance Checking Using BPMN-Q and Temporal Logic, in: Marlon Dumas, Manfred Reichert, and Ming-Chien Shan (eds.): Business Process Management, Springer: Berlin et al., 326-341.

Awad, Ahmed, Sergey Smirnov, and Mathias Weske (2009a): Resolution of Compliance Violation in Business Process Models: A Planning-Based Approach, in: Robert Meersman, Tharam Dillon, and Pilar Herrero (eds.): On the Move to Meaningful Internet Systems: OTM 2009, Springer: Berlin et al., 6-23.

Awad, Ahmed, Sergey Smirnov, and Mathias Weske (2009b): Towards Resolving Compliance Violations in Business Process Models, CEUR Workshop Proceedings, 459: 1-15.

Awad, Ahmed and Mathias Weske (2009): Visualization of Compliance Violation Using Anti-Patterns, BPT Technical Report, http://bpt.hpi.uni-potsdam.de/pub/Public/Ahmed Awad/VoV.pdf (Access date: 2012-09-21).

Awad, Ahmed and Mathias Weske (2010): Visualization of Compliance Violation in Business Process Models, in: Stefanie Rinderle-Ma, Shazia Sadiq, and Frank Leymann (eds.): Business Process Management Workshops (BPM 2009), Springer: Berlin et al., 182-193.
BaFin (2010): Rundschreiben 11/2010 (BA) - Mindestanforderungen an das Risikomanagement - MaRisk, http://www. bafin.de/SharedDocs/Veroeffentlichungen/DE/Rundschreibe n/rs_1011_ba_marisk.html (Access date: 2012-09-21).

Becker, Axel, Walter Gruber, and Dirk Wohlert (eds.) (2006): Handbuch MaRisk: Mindestanforderungen an das Risikomanagement in der Bankpraxis, Knapp: Frankfurt am Main.

Breuker, Dominik, Hanns Alexander Dietrich, Johannes Püster, Matthias Steinhorst, Jörg Becker, and Patrick Delfmann (2012): Eine empirische Studie zur strukturellen Komplexität konzeptioneller Modelle Grundlegung eines effizienten Ansatzes zur strukturellen Modellanalyse, in: Dirk Christian Mattfeld and S. Robra-Bissantz (eds.): Multikonferenz Wirtschaftsinformatik 2012, Gito: Berlin, 1688-1701.

Cantor, Georg (1895): Beiträge zur Begründung der transfiniten Mengenlehre, Mathematische Annalen, 46 (4): 481-512.

Chakrabarti, Deepayan and Christos Faloutsos (2006): Graph Mining: Laws, Generators, and Algorithms, ACM Computing Surveys, 38 (1): Article 2.

Cimatti, Alessandro, Edmund Clarke, Enrico Giunchiglia, Fausto Giunchiglia, Marco Pistore, Marco Roveri, Roberto Sebastiani, and Armando Tacchella (2002): NuSMV 2: An OpenSource Tool for Symbolic Model Checking, in: Ed Brinksma and Kim G. Larsen (eds.): $14^{\text {th }}$ International Conference on Computer Aided Verification (CAV 2002), Springer: Berlin et al., 359-364.

Clarke, Edmund M. Jr., Orna Grumberg, and Doron A. Peled (2000): Model Checking, MIT Press: Cambridge, MA, USA.

Conte, Donatello, Pasquale Foggia, Carlo Sansone, and Mario Vento (2004): Thirty Years Of Graph Matching, International Journal of Pattern Recognition and Artificial Intelligence, 18 (3): 265-298.

Damaggio, Elio, Alin Deutsch, Richard Hull, and Victor Vianu (2011): Automatic Verification of Data-Centric Business Processes, in: Stefanie Rinderle-Ma, Farouk Toumani, and Karsten Wolf (eds.): $9^{\text {th }}$ International Conference on Business Process Management (BPM 2011), Springer: Berlin et al., 316.

Davenport, Thomas H. and Donna B. Stoddard (1994): Reengineering: Business Change of Mythic Proportions?, MIS Quarterly, 18 (2): 121-127.

Davis, Islay, Peter Green, Michael Rosemann, Marta Indulska, and Stan Gallo (2006): How Do Practitioners Use Conceptual Modeling in Practice?, Data \& Knowledge Engineering, 58 (3): 358-380.

Delfmann, Patrick, Sebastian Herwig, and Lukasz Lis (2009): Unified Enterprise Knowledge Representation With Conceptual Models: Capturing Corporate Language in Naming Conventions, in: ICIS 2009 Proceedings, Paper 45, http://aisel.aisnet.org/icis2009/45 (Access date: 2012-0924).

DeToro, Irving and Thomas McCabe (1997): How to Stay Flexible and Elude Fads, Quality Progress, 30 (3): 55-60.

Diestel, Reinhard (2010): Graph Theory, Springer: Berlin et al.

Dorn, Frederic (2010): Planar Subgraph Isomorphism Revisited, in: Jean-Yves Marion and Thomas Schwentick (eds.): $27^{\text {th }}$ International Symposium on Theoretical Aspects of Computer Science, Leibniz-Zentrum für Informatik: Wadern, 263-274.

El Kharbili, Marwane, Ana Karla Alves De Medeiros, Sebastian Stein, and Wil M. P. van der Aalst (2008): Business Process Compliance Checking: Current State and Future Challenges, 
in: Peter Loos (ed.): Modellierung betrieblicher Informationssysteme (MoBIS 2008), Gesellschaft für Informatik: Bonn, 107-113.

El Kharbili, Marwane, Sebastian Stein, Ivan Markovic, and Elke Pulvermueller (2008): Towards a Framework for Semantic Business Process Compliance Management, CEUR Workshop Proceedings, 339: 1-15.

Elgammal, Amal, Oktay Turetken, Willem-Jan van den Heuvel, and Mike Papazoglou (2010): Root-Cause Analysis of Design-Time Compliance Violations on the Basis of Property Patterns, in: Paul P. Maglio, Mathias Weske, Jian Yang, and Marcelo Fantinato (eds.): Service-Oriented Computing, Springer: Berlin et al., 17-31.

Elzinga, D. Jack, Tomas Horak, Chung-Yee Lee, and Charles Bruner (1995): Business Process Management: Survey and Methodology, IEEE Transactions on Engineering Management, 42 (2): 119-128.

Eshuis, Rik (2006): Symbolic Model Checking of UML Activity Diagrams, ACM Transactions on Software Engineering and Methodology, 15 (1): 1-38.

Eshuis, Rik and Roel Wieringa (2004): Tool Support for Verifying UML Activity Diagrams, IEEE Transactions on Software Engineering, 30 (7): 437-447.

Foerster, Alexander, Gregor Engels, and Tim Schattkowsky (2005): Activity Diagram Patterns for Modeling Quality Constraints in Business Processes, in: Lionel Briand and Clay Williams (eds.): Model Driven Engineering Languages and Systems, Springer: Berlin et al., 2-16.

Foerster, Alexander, Gregor Engels, Tim Schattkowsky, and Ragnhild Van Der Straeten (2007): Verification of Business Process Quality Constraints Based on Visual Process Patterns, in: First Joint IEEE/IFIP Symposium on Theoretical Aspects of Software Engineering (TASE 2007), IEEE Computer Society: Los Alamitos, CA, 197-208.

Georges, Andy, Dries Buytaert, and Lieven Eeckhout (2007): Statistically Rigorous Java Performance Evaluation, $A C M$ SIG-PLAN Notices, 42 (10): 57-76.

Gerstlberger, Wolfgang, Michael Kreuzkamp, Peter E. Harland, and Vitali Altholz (2010): Implementation of MaRisk and Sustainability Aspects of Innovation, Economic and Environmental Studies, 10 (4): 357-378.

Ghose, Aditya and George Koliadis (2007): Auditing Business Process Compliance, in: Bernd J. Krämer, Kwei-Jay Lin, and Priya Narasimhan (eds.): Service-Oriented Computing (ICSOC 2007), Springer: Berlin et al., 169-180.

Ginzberg, Michael J. (1981): Early Diagnosis of MIS Implementation Failure: Promising Results and Unanswered Questions, Management Science, 27 (4): 459-478.

Goedertier, Stijn and Jan Vanthienen (2006): Designing Compliant Business Processes With Obligations and Permissions, in: Johann Eder and Schahram Dustdar (eds.): Business Process Management Workshops (BPM 2006), Springer: Berlin et al., 5-14.

Governatori, Guido and Zoran Milosevic (2006): A Formal Analysis of a Business Contract Language, International Journal of Cooperative Information Systems, 15 (4): 659-685.

Governatori, Guido, Zoran Milosevic, and Shazia Sadiq (2006): Compliance Checking Between Business Processes and Business Contracts, in: $10^{\text {th }}$ IEEE International Enterprise Distributed Object Computer Conference, IEEE Computer Society: Los Alamitos, CA, 221-232.

Governatori, Guido and Antonino Rotolo (2010): A Conceptually Rich Model of Business Process Compliance, in: Sebastian Link and Aditya K. Ghose (eds.): $7^{\text {th }}$ Asia-Pacific
Conference on Conceptual Modelling (APCCM 2010), Australian Computer Society: Darlinghurst, 3-12.

Grant, Delvin (2002): A Wider View of Business Process Reengineering, Communications of the ACM, 45 (2): 85-90.

Hajiaghayi, Mohammad and Naomi Nishimura (2007): Subgraph Isomorphism, Log-Bounded Fragmentation, and Graphs of (Locally) Bounded Treewidth, Journal of Computer and System Sciences, 73 (5): 755-768.

Hammer, Michael and James Champy (1993): Reengineering the Corporation: A Manifesto for Business Revolution, HarperBusiness: New York, NY.

Harmon, Paul (2003): Business Process Change: A Manager's Guide to Improving, Redesigning, and Automating Processes, Morgan-Kaufmann: Amsterdam et al.

Hevner, Alan R., Salvatore T. March, Jinsoo Park, and Sudha Ram (2004): Design Science in Information Systems Research, MIS Quarterly, 28 (1): 75-105.

Hicks, Illya V. (2004): Branch Decompositions and Minor Containment, Networks, 43 (1): 1-9.

Hinz, Sebastian, Karsten Schmidt, and Christian Stahl (2005): Transforming BPEL to Petri Nets in: Wil M. P. van der Aalst, Boualem Benatallah, Fabio Casati, and Francisco Curbera (eds.): $3^{\text {rd }}$ International Conference on Business Process Management (BPM 2005), Springer: Berlin et al., 220-235.

Hoffmann, Jörg, Ingo Weber, and Guido Governatori (2012): On Compliance Checking for Clausal Constraints in Annotated Process Models, Information Systems Frontiers, 14 (2): 155177.

Holzmann, Gerard J. (1997): The Model Checker SPIN, IEEE Transactions on Software Engineering, 23 (5): 279-295.

Keller, Gerhard, Markus Nüttgens, and August-Wilhelm Scheer (1992): Semantische Prozeßmodellierung auf der Grundlage „Ereignisgesteuerter Prozeßketten (EPK)“, Institut für Wirtschaftsinformatik: Saarbrücken.

Khaluf, Lial, Christian Gerth, and Gregor Engels (2011): Pattern-Based Modeling and Formalizing of Business Process Quality Constraints, in: Haralambos Mouratidis and Colette Rolland (eds.): $23^{\text {rd }}$ International Conference on Advanced Information Systems Engineering (CAiSE 2011), Springer: Berlin et al., 521-535.

Knuplesch, David, Linh Thao Ly, Stefanie Rinderle-Ma, Holger Pfeifer, and Peter Dadam (2010): On Enabling DataAware Compliance Checking of Business Process Models, in: Jeffrey Parsons, Motoshi Saeki, Peretz Shoval, Carson Woo, and Yair Wand (eds.): $29^{\text {th }}$ International Conference on Conceptual Modeling (ER 2010), Springer: Berlin et al., 332346.

Kokash, Natallia and Farhad Arbab (2009): Formal Behavioral Modeling and Compliance Analysis for ServiceOriented Systems, in: Frank S. Boer, Marcello M. Bonsangue, and Eric Madelaine (eds.): Formal Methods for Components and Objects, Springer: Berlin et al., 21-41.

Kuester, Jochen M., Ksenia Ryndina, and Harald Gall (2007): Generation of Business Process Models for Object Life Cycle Compliance, in: Gustavo Alonso, Peter Dadam, and Michael Rosemann (eds.): $5^{\text {th }}$ International Conference on Business Process Management (BPM 2007), Springer: Berlin et al., 165-181.

Kumar, Akhil and Rong Liu (2008): A Rule-Based Framework Using Role Patterns for Business Process Compliance, in: Nick Bassiliades, Guido Governatori, and Adrian Paschke (eds.): Rule Representation, Interchange and Reasoning on the Web (RuleML 2008), Springer: Berlin et al., 58-72. 
Lee, Allen S. and Richard L. Baskerville (2003): Generalizing Generalizability in Information Systems Research, Information Systems Research, 14 (3): 221-243.

Levy, Yair and Timothy J. Ellis (2006): A Systems Approach to Conduct an Effective Literature Review in Support of Information Systems Research, Informing Science, 9: 181-212.

Liu, Ying, Samuel Müller, and Ke Xu (2007): A Static Compliance-Checking Framework for Business Process Models, IBM Systems Journal, 46 (2): 335-361.

Lohmann, Niels and Karsten Wolf (2010): How to Implement a Theory of Correctness in the Area of Business Processes and Services, in: Richard Hull, Jan Mendling, and Stefan Tai (eds.): $8^{\text {th }}$ International Conference on Business Process Management (BPM 2010), Springer: Berlin et al., 61-77.

Lu, Ruopeng, Shazia Sadiq, and Guido Governatori (2008a): Compliance Aware Business Process Design, in: Arthur ter Hofstede, Boualem Benatallah, and Hye-Young Paik (eds.): Business Process Management Workshops (BPM 2007), Springer: Berlin et al., 120-131.

Lu, Ruopeng, Shazia Sadiq, and Guido Governatori (2008b): Measurement of Compliance Distance in Business Processes, Information Systems Management, 25 (4): 344-355.

Lucas Jr., Henry C. (1975): Performance and the Use of an Information System, Management Science, 21 (8): 908-919.

Ly, Linh Thao, Kevin Goeser, Stefanie Rinderle-Ma, and Peter Dadam (2008): Compliance of Semantic Constraints: A Requirements Analysis for Process Management Systems, CEUR Workshop Proceedings, 339: 31-45.

Ly, Linh Thao, Stefanie Rinderle-Ma, and Peter Dadam (2006): Semantic Correctness in Adaptive Process Management Systems, in: Schahram Dustdar, José Luiz Fiadeiro, and Amit P. Sheth (eds.): $4^{\text {th }}$ International Conference on Business Process Management (BPM 2006), Springer: Berlin et al., 193-208.

Ly, Linh Thao, Stefanie Rinderle-Ma, and Peter Dadam (2010): Design and Verification of Instantiable Compliance Rule Graphs in Process-Aware Information Systems, in: Barbara Pernici (ed.): Advanced Information Systems Engineering, Springer: Berlin et al., 9-23.

Ly, Linh Thao, Stefanie Rinderle-Ma, Kevin Göser, and Peter Dadam (2009): On Enabling Integrated Process Compliance With Semantic Constraints in Process Management Systems: Requirements, Challenges, Solutions, Information Systems Frontiers, 14 (2): 195-219.

Ly, Linh Thao, Stefanie Rinderle-Ma, and Peter Dadam (2008): Integration and Verification of Semantic Constraints in Adaptive Process Management Systems, Data \& Knowledge Engineering, 64 (1): 3-23.

March, Salvatore T. and Gerald F. Smith (1995): Design and Natural Science Research on Information Technology, Decision Support Systems, 15 (4): 251-266.

Monakova, Ganna, Oliver Kopp, Frank Leymann, Simon Moser, and Klaus Schäfers (2009): Verifying Business Rules Using an SMT Solver for BPEL Processes, in: Witold Abramowicz, Leszek A. Maciaszek, Ryszard Kowalczyk, and Andreas Speck (eds.): Business Process, Services Computing and Intelligent Service Management (BPSC 2009), Gesellschaft für Informatik: Bonn, 81-94.

Mueller, Jens (2010): Strukturbasierte Verifikation von BPMN-Modellen, Dissertation, University of Tübingen: Tübingen, http://www-ti.informatik.uni-tuebingen.de/ spruth/DiplArb/DissMueller.pdf (Access date: 2012-09-27). Namiri, Kioumars and Nenad Stojanovic (2007): PatternBased Design and Validation of Business Process Compliance, in: Robert Meersman and Zahir Tari (eds.): On the Move to Meaningful Internet Systems: OTM 2007, Springer: Berlin et al., 59-76.

Object Management Group (2005): Unified Modeling Language: Infrastructure, http:// www.omg.org/spec/UML/ 2.0/Infrastructure/PDF (Access date: 2012-04-10).

Object Management Group (2011): Business Process Model and Notation (BPMN), http://www.omg.org/spec/BPMN/ 2.0/PDF (Access date: 2012-04-10).

Organization for the Advancement of Structured Information Standards (2007): Web Services Business Process Execution Language Version 2.0, http://docs.oasis-open.org/wsbpel/ 2.0/wsbpel-v2.o.pdf (Access date: 2012-09-18).

Orriëns, Bart and Jian Yang (2005): Specification and Management of Policies in Service Oriented Business Collaboration, in: Wil M. P. van der Aalst, Boualem Benatallah, Fabio Casati, and Francisco Curbera (eds.): $3^{\text {rd }}$ International Conference on Business Process Management (BPM 2005), Springer: Berlin et al., 422-427.

Österle, Hubert, Jörg Becker, Ulrich Frank, Thomas Hess, Dimitris Karagiannis, Helmut Krcmar, Peter Loos, Peter Mertens, Andreas Oberweis, and Elmar J. Sinz (2010): Memorandum zur gestaltungsorientierten Wirtschaftsinformatik, Schmalenbachs Zeitschrift für betriebswirtschaftliche Forschung, 62 (6): 664-672.

Peffers, Ken, Tuure Tuunanen, Marcus A. Rothenberger, and Samir Chatterjee (2007): A Design Science Research Methodology for Information Systems Research, Journal of Management Information Systems, 24 (3): 45-77.

Peterson, James L. (1977): Petri Nets, ACM Computing Surveys, 9 (3): 223-252.

Raduescu, Corina, Hui Min Tan, Malini Jayaganesh, Wasana Bandara, Michael zur Muehlen, and Sonja Lippe (2006): A Framework of Issues in Large Process Modeling Projects, in: Jan Ljungberg (ed.): $14^{\text {th }}$ European Conference on Information Systems (ECIS 2006), Göteborg, 1-12.

Recker, Jan, Michael Rosemann, Marta Indulska, and Peter Green (2009): Business Process Modeling: A Comparative Analysis, Journal of the Association for Information Systems, $10(4): 333-363$

Riege, Christian, Jan Saat, and Tobias Bucher (2009): Systematisierung von Evaluationsmethoden in der gestaltungsorientierten Wirtschaftsinformatik, in: Jörg Becker, Helmut Krcmar, and Björn Niehaves (eds.): Wissenschaftstheorie und gestaltungsorientierte Wirtschaftsinformatik, Physica: Heidelberg, 69-86.

Rosemann, Michael and Iris Vessey (2008): Toward Improving the Relevance of Information Systems Research to Practice: The Role of Applicability Checks, MIS Quarterly, 32 (1): 1-22.

Sadiq, Shazia, Guido Governatori, and Kioumars Namiri (2007): Modeling Control Objectives for Business Process Compliance, in: Gustavo Alonso, Peter Dadam, and Michael Rosemann (eds.): $5^{\text {th }}$ International Conference on Business Process Management (BPM 2007), Springer: Berlin et al., 149-164.

Sarbanes-Oxley Act (2002): Public Law 107-204 107 Congress, http://www.gpo.gov/fdsys/pkg/PLAW-107publ204 /pdf/PLAW-107publ204.pdf (Access date: 2012-04-10).

Schleicher, Daniel, Tobias Anstett, Frank Leymann, and David Schumm (2010): Compliant Business Process Design Using Refinement Layers, in: Robert Meersman, Tharam Dillon, and Pilar Herrero (eds.): On the Move to Meaningful Internet Systems: OTM 2010, Springer: Berlin et al., 114-131. 
Schmidt, Karsten (2000): LoLA: A Low Level Analyser, in: Mogens Nielsen and Dan Simpson (eds.): $21^{\text {st }}$ International Conference on Application and Theory of Petri Nets. (ICATPN 200O), Springer: Berlin et al., 465-476.

Schrader, Ulf and Thorsten Hennig-Thurau (2009): VHBJOURQUAL2: Method, Results, and Implications of the German Academic Association for Business Research's Journal Ranking, BuR - Business Research, 2 (2): 180-204.

Schumm, David, Oktay Turetken, Natallia Kokash, Amal Elgammal, Frank Leymann, and Willem-Jan van den Heuvel (2010): Business Process Compliance Through Reusable Units of Compliant Processes in: Florian Daniel and Federico Michele Facca (eds.): Current Trends in Web Engineering, Springer: Berlin et al., 325-337.

Simon, Herbert A. (1996): The Sciences of the Artificial, MIT Press: Cambridge, MA.

Soffer, Pnina and Yair Wand (2004): Goal-Driven Analysis of Process Model Validity, in: Anne Persson and Janis Stirna (eds.): $16^{\text {th }}$ International Conference on Advanced Information Systems Engineering (CAiSE 2004), Springer: Berlin et al., 229-319.

Stewart, David W., Prem N. Shamdasani, and Dennis W. Rook (2007): Focus groups: Theory and practice, Sage: Thousand Oaks, CA, et al.

Swanson, E. Burton (1987): Information Channel Disposition and Use, Decision Sciences, 18 (1): 131-145.

Thomas, Oliver and Michael Fellmann (2009): Semantic Process Modeling - Design and Implementation of an Ontology-Based Representation of Business Processes, Business \& Information Systems Engineering, 1 (6): 438-451.

Trčka, Nikola, Wil M. P. van der Aalst, and Natalia Sidorova (2009): Data-Flow Anti-patterns: Discovering Data-Flow Errors in Workflows, in: Pascal van Eck, Jaap Gordijn, and Roel Wieringa (eds.): $21^{\text {st }}$ International Conference on Advanced Information Systems Engineering (CAiSE 20o9), Springer: Berlin et al., 425-439.

Ullmann, Julian R. (1976): An Algorithm for Subgraph Isomorphism, Journal of the ACM, 23 (1): 31-42.

Vom Brocke, Jan, Alexander Simons, Björn Niehaves, Kai Riemer, Ralf Plattfaut, and Anne Cleven (2009): Reconstructing the Giant: On the Importance of Rigour in Documenting the Literature Search Process, in: S. Newell (ed.): $17^{\text {th }}$ European Conference on Information Systems (ECIS 2009), Verona, 2206-2217.

Wang, Harry Jiannan and J. Leon Zhao (2011): ConstraintCentric Workflow Change Analytics, Decision Support
Systems, 51 (3): 562-575.

Webster, Jane and Richard T. Watson (2002): Analyzing the Past to Prepare for the Future: Writing a Literature Review, MIS Quarterly, 26 (2): xiii-xxiii.

Woerzberger, René, Thomas Kurpick, and Thomas Heer (2008a): Checking Correctness and Compliance of Integrated Process Models, in: Viorel Negru, Tudor Jebelean, Dana Petcu, and Daniela Zaharie (eds.): $10^{\text {th }}$ International Symposium on Symbolic and Numeric Algorithms for Scientific Computing, IEEE Computer Society: Los Alamitos, CA, 576583 .

Woerzberger, René, Thomas Kurpick, and Thomas Heer (2008b): On Correctness, Compliance and Consistency of Process Models, in: 2008 Workshops on Enabling Technologies: Infrastructure for Collaborative Enterprises, IEEE Computer Society: Los Alamitos, CA, 251-252.

Wolter, Christian and Christoph Meinel (2010): An Approach to Capture Authorisation Requirements in Business Processes, Requirements Engineering, 15 (4): 359-373.

Wolter, Christian, Philip Miseldine, and Christoph Meinel (2009): Verification of Business Process Entailment Constraints Using SPIN, in: Fabio Massacci, Samuel T. Redwine, and Nicola Zannone (eds.): Engineering Secure Software and Systems, Springer: Berlin et al., 1-15.

Xiangpeng, Zhao, Antonio Cerone, and Padmanabhan Krishnan (2006): Verifying BPEL Workflows Under Authorisation Constraints, in: Schahram Dustdar, José Luiz Fiadeiro, and Amit P. Sheth (eds.): $4^{\text {th }}$ International Conference on Business Process Management (BPM 2006), Springer: Berlin et al., 439-444.

Zairi, Mohamed (1997): Business Process Management: A Boundaryless Approach to Modern Competitiveness, Business Process Management Journal, 3 (1): 64-80.

Zur Muehlen, Michael, Marta Indulska, and Gerrit Kamp (2007): Business Process and Business Rule Modeling Languages for Compliance Management: A Representational Analysis, in: John Grundy, Sven Hartmann, Alberto H. F. Laender, Leszek A. Maciaszek, and John F. Roddick (eds.): Tutorials, Posters, Panels and Industrial Contributions at the $26^{\text {th }}$ International Conference on Conceptual Modeling (ER 2007), Australian Computer Society: Auckland, 127-132.

Zur Muehlen, Michael and Jan Recker (2008): How Much Language is Enough? Theoretical and Practical Use of the Business Process Modeling Notation, in: Zohra Bellahsène and Michel Léonard (eds.): $2 O^{\text {th }}$ International Conference on Advanced Information Systems Engineering (CAiSE 20o8), Springer: Berlin et al., 465-479. 


\section{Biographies}

Jörg Becker is a full professor and Head of the Department of Information Systems at the University of Münster, Germany. He is the Managing Director of the European Research Center for Information Systems (ERCIS). Jörg is Editor in Chief of the international journal Information Systems and eBusiness Management and serves on various editorial boards. His work has appeared in several journals (e.g., Communications of the AIS, Information Systems Journal, Scandinavian Journal of Information Systems) and was presented on international conferences (e.g., ICIS, AMCIS, ECIS). Jörg's research interests include information management, process management, retail IS, and strategic IT-management consulting.

Patrick Delfmann is a senior researcher at the Department of Information Systems at the University of Münster. He holds a Ph.D. and a postdoctoral degree in Information Systems. Patrick was the coordinator of several research projects, funded by national and international funding organizations. He teaches at the University of Münster and has been a visiting professor in Moscow, Vienna, and Biel. His work comprises more than 60 scientific papers, many of which have appeared in high-ranked international proceedings and journals. His main research interests are Conceptual Modeling, Reference Modeling, Model Analysis, Semantic Disambiguation and Business Process Compliance Management.

Mathias Eggert is a research assistant at the Department of Information Systems at the University of Münster, Germany. He studied Information Systems at the universities in Ingolstadt and Stuttgart-Hohenheim and he holds a scholarship of the Konrad-Adenauer foundation. His research interests comprise Business Process Management, Compliance, Business Intelligence and reporting in financial industries.

Sebastian Schwittay works for Deutsche Bank and received his degree in Information Systems at the University of Muenster. He is interested in Business Process Management and Compliance-related challenges of BPM. 